
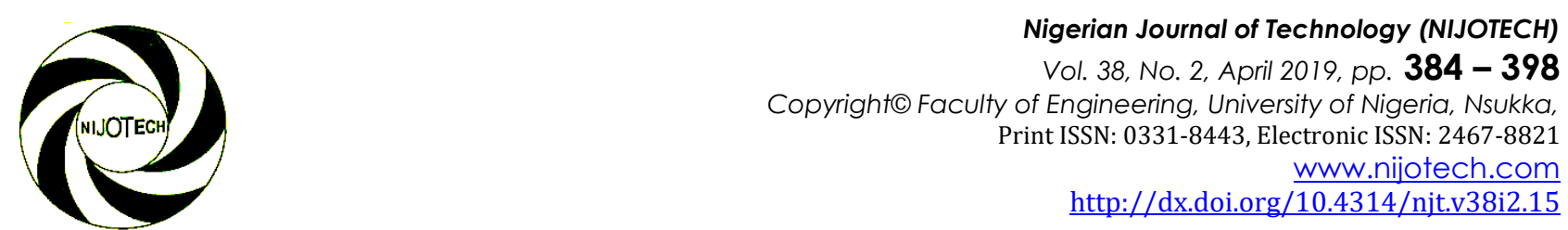

\title{
NUMERICAL STUDY OF HIGH DENSITY POLYETHYLENE -PCM CAPSULES FOR PASSIVE COOLING APPLICATION IN INTERMODAL STEEL BUILDING SPACE ENVELOPE
}

\author{
A. N. Udosen*

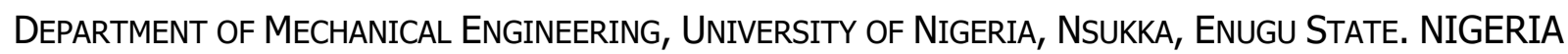 \\ E-mail address: abasiafak.udosen@unn.edu.ng
}

\begin{abstract}
The Intermodal Steel Building envelope commonly called shipping container or 'the conex box' is gradually becoming a common option for occupants who use them for commercial or residential purposes due to its relatively cheap cost compared to conventional brick or concrete structure houses. The conex box is mainly made of high density steel with high thermal conductivity, which results to increased and uncomfortable indoor space temperatures for its occupants. In Nigeria, the indoor space temperature of the conex box is often high because of the relatively high daytime ambient temperature, usually $30^{\circ} \mathrm{C}$ and above especially in the Northern part of Nigeria. This has led to the dependence on mechanical air conditioning to achieve human thermal comfort within the conex box. The net effect of this will be the over dependence on the already stretched and insufficient power from grid connected electricity. This work investigates numerically the potentials of high density polyethylene PCM (phase change material) capsules for passive cooling application in a typical intermodal steel building space enclosure. Numerical results obtained from the Matlab programme software showed that exposing the HDPE-PCM panel system to high ambient temperature is capable of causing significant ambient temperature depressions of $7.1-10.2^{\circ} \mathrm{C}$ for four simulation days. It is recommended that further simulation and experimental study is carried out with reverse suction DC fan(s) placed at strategic locations on the steel container walls for air quality recirculation and removal. The results obtained from this study shows that the modelled HDPE-PCM panel system for passive cooling application in shipping container homes, is possible and when properly implemented has the capability of reducing over dependency on mechanical air conditioning systems even for conventional concrete and brick building structures.
\end{abstract}

Keywords: Latent heat; Paraffin wax; Polyethylene, Passive Cooling; Conex Box;

\section{INTRODUCTION}

Passive cooling uses free, renewable sources of energy such as the sun and wind to provide cooling, ventilation and lighting needs for a household [1]. Passive cooling has the potentials to be combined with or completely eliminate the need to use mechanical cooling strategies to provide thermal comfort for occupants [1-2]. It can also reduce levels of energy use and environmental impacts such as greenhouse gas emissions. Passive space cooling with Phase Change Materials (PCMs) has grown recently in the last decade offering less cost for its applications with reduced environmental hazard concerns. Phase Change Material typically referred to as latent heat storage material is sensitive to source or surrounding temperature fluctuations. In its operation, the chemical bonds within the PCM breaks up and the material changes its phase from solid to liquid or liquid to solid. This phase change is either referred to as charging or discharging process. When the PCM material begins to melt its temperature remains approximately constant until the melting process is completed. The heat stored during the phase change process (melting process) of the material is called

* Author, tel: +234-813-818- 8878 
Latent Heat. The incorporation of PCMs for thermal applications such as space heating/cooling, solar cooking, large concentrating solar power plants etc, have received much attention and investigations in the industrialized countries in the past four to five decades because of the ever increasing energy cost and environmental concerns. According to [3], the most promising of the storage media available are the normal paraffin because of their very good latent heat storage capacity, high heat of fusion and high volumetric energy densities to accommodate small temperature swings. The integration of PCMs in building have been investigated, especially with the advent of PCM implemented in gypsum board, plaster, concrete and other wall covering materials. Advanced countries, presently mainly integrate PCM in passive solar building systems for space heating and in active systems for water heating in buildings. An example is the storage of summer heat for winter space heating, and storage of solar energy for hot water use at night. In the United States, light weight building construction practice is common place allowing for light weight PCM system to be installed. Again in [2], the authors add that systems like wallboard and panels containing PCM that melts at room temperature is suitable for lightweight structures where the PCM also serves as a panel structural component to provide additional wall thermal mass. The authors in [4], studied cases where PCM was directly integrated into building materials by mixing granulated paraffin wax with concrete or cement. They observed that this method interfered with building structures because the concrete strength was compromised while the PCM properties changed and caused a major leakage problem that corrodes the steel bars in building structures. A prominent method of integration of PCMs in construction materials such as paints, cement, lime, mortar, etc has been found to be the microencapsulation technology. This work is an attempt to investigate the possibilities of using high density polyethylene PCM (paraffin wax) capsules for space cooling of commonly used Intermodal steel building envelopes.

\section{REVIEW OF RELEVANT WORKS ON PASSIVE HEATING/COOLING APPLICATION OF PCMS IN HEATING VENTILATION AND AIR- CONDITIONING (HVAC) LOW ENERGY BUILDINGS}

Passive methods integrate PCMs with appropriate melting temperatures mostly adopted into building materials such as walls and ceiling, or inside of ducting at suitable locations (e.g window openings) basically to store cold from night air for daytime cooling or vice versa. Akar and Medved [5] noted that passively integrated Thermal Energy Storage (TES) can be used with solar energy or other renewable energy sources to facilitate effective energy managements. Hybrid system which integrates both active and passive cooling/heating strategies can also be utilized together to decrease HVAC energy requirements and operating costs and improve comfort in indoor living and work spaces [3]. According to [3], an important performance factor in the design of passive cooling systems using latent TES is the appropriate PCM melting point. A numerical assessment of the performance of a vertical cylinder filled with spherical encapsulated RT20 paraffin PCM was studied by [4]. The authors numerically modeled and developed a latent heat thermal energy storage (LHTES) device to identify the parameters that have influence on the LHTES's thermal response in order to determine the optimum phase-change temperature, and to form the LHTES's temperature-response function which defines the LHTES's outlets-air temperature for a periodic variation of the inlet ambient air temperature. The temperature-response was then integrated into the TRNSYS building thermal response model. Numerical simulations showed that a PCM with melting temperature between 20 and $22^{\circ} \mathrm{C}$ is the most suitable for free cooling in the case of a continental Europe climate conditions. They stated that the analyses of the temperatures in a low-energy building showed that free cooling with an LHTES is an effective cooling technique. Recent developments in PCM use in building envelope for passive space cooling have been reviewed by [6]. These authors investigated the ability to store solar power during winter days and reject heat during summer nights so as to reduce diurnal indoor temperature fluctuations. The PCMs they used, had the melting point of an average room temperature and obtained results showed that PCMs are useful for stabilizing room temperature during daytime, increasing comfort, and decreasing HVAC capacity. The work by [7], numerically assessed and experimentally verified several paraffin(s) and eutectics blends for floor and ceiling-free cooling. It was observed that ventilation occurred during cooler night times. Thus, a PCM with proper melting temperature incorporated in the air duct permits the provision of cooler day-time room temperatures and the HVAC energy consumption during warm days is thereby reduced. In [5], a fan/duct model for night 
ventilation of a room where TRNSYS was used to assess the building thermal response which was validated using an experimental data. Paraffin RT20 PCM was also used in this simulation as the latent TES media which facilitated the night ventilation for free cooling. Their results revealed a reduction in mechanical ventilation system capacity. In the same vein, authors in [8], developed a new insulating wall incorporating a PCM as insulation. The PCM used acted as a capacitor, receiving and rejecting large quantities of energy as it changes phase. Structural insulated panels were adopted to incorporate PCMs to create a distributed thermal mass and a noncorrosive /nontoxic paraffin PCM was used to fill the tubes inserted into the wall. Their strategy increased the thermal barrier effect, providing a stable room temperature variation through a heat flux reduction. In the work done by [9], the authors numerically and experimentally examined the use of latent TES for free cooling for a range of climate conditions. They suggested an optimal latent TES based on the ratio of PCM mass and ventilation air volume flow rate. The authors concluded that the PCM with the widest phase change temperature range of $12 \mathrm{~K}$ was found to be the most efficient for the climate conditions analyzed. The optimal PCM mass for the free cooling of a room was found to be $1-1.5 \mathrm{~kg}$ per $\mathrm{m}^{3} / \mathrm{h}$ of fresh ventilation air.

\section{HDPE-PCM PANEL SIMULATED MODEL DESCRIPTION}

The HDPE-PCM panel medium is the storage model used for this study and was generated using the solid works simulation tool. The HDPE-PCM panel medium of HDPE shelled balls or capsules arranged on a specially constructed wire gauze, filled with technical grade paraffin wax as the PCM. The HDPE-PCM panel medium is externally insulated with expanded polystyrene board on the sides to avoid heat losses. The capsule shells have HDPE coating thickness of $0.8 \mathrm{~mm}$ with capsule outer diameter of $60 \mathrm{~mm}$. The method of paraffin packaging is by microencapsulation. The thermophysical properties of the PCM and HDPE are presented in Tables 1 and 2 respectively. The HDPE panel setup consist of HDPE capsules arranged in a panel medium where its thermodynamic and structural effects on the capsule are negligible in this study. The paraffin used is ecologically/environmentally friendly and 100\% recyclable. The paraffin is mainly used in low energy buildings for cooling due to its melting temperatures between $23-25^{\circ} \mathrm{C}$ and with latent heat of fusion between $214.4 \mathrm{~kJ} / \mathrm{kg}$. The surrounding heat transfer fluid (HTF) for the system is ambient air, propelled using a high pressure axial flow fan placed at the airinlet channel of the panel medium with each fan speed of 500rpm. The realistic behaviour of the PCM modelled in this study during the melting and solidification processes was observed and reported by [10] using the differential scanning calorimetry (DSC) measurements with Mettler TA 4000 thermo-analysis equipment.

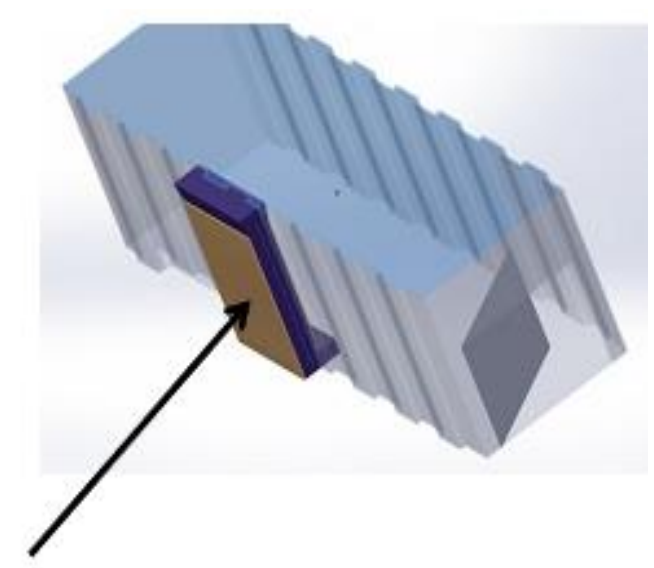

HDPE-PCM Panel unit

Figure 1: Intermodal steel building envelope Model used for the study

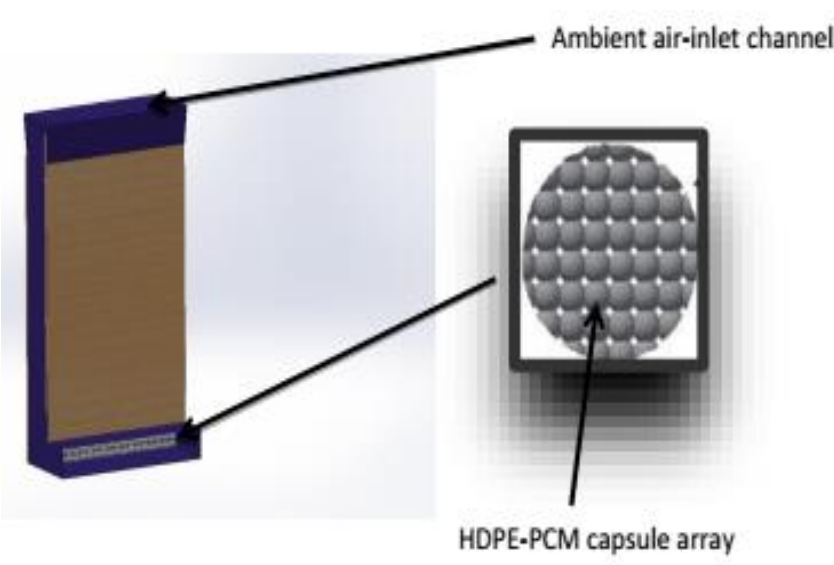

Figure 2: HDPE-PCM Panel Simulated Model Schematic

Table 1: Thermophysical properties of a paraffin wax phase change material used for the study.

\begin{tabular}{ll}
\hline Properties & Value \\
\hline Specific heat capacity (solid) & $2 \mathrm{KJkg}^{-1} \mathrm{~K}^{-1}$ \\
Specific heat capacity (liquid) & $3.2 \mathrm{KJkg}^{-1} \mathrm{~K}^{-1}$ \\
Thermal conductivity (solid) & $2 \mathrm{Wm}^{-1} \mathrm{~K}^{-1}$ \\
Thermal conductivity (liquid) & $0.55 \mathrm{Wm}^{-1} \mathrm{~K}^{-1}$ \\
Enthalpy of fusion & $214.4 \mathrm{kJkg}^{-1}$ \\
Density (solid) & $1500 \mathrm{kgm}^{-3}$ \\
Density (liquid) & $1530 \mathrm{kgm}^{-3}$ \\
Viscosity & $1.07 \times 10^{-6} \mathrm{kgm}^{-1} \mathrm{~S}^{-1}$ \\
\hline
\end{tabular}


Source [12]

Table 2: Thermophysical properties of HDPE capsule

\begin{tabular}{ll}
\multicolumn{2}{c}{ material used for the study. } \\
\hline Properties & Value \\
\hline Thermal diffusivity & $1.96 \times 10^{-7} \mathrm{~m}^{2} \mathrm{~s}^{-1}$ \\
Thermal conductivity & $0.35 \mathrm{Wm}^{-1} \mathrm{~K}^{-1}$ \\
Density & $940 \mathrm{kgm}^{-3}$ \\
Specific heat capacity & $1.9 \mathrm{KJkg}^{-1} \mathrm{~K}^{-1}$ \\
Melting point & $108^{\circ} \mathrm{C}$ \\
Emissivity & $0.8-0.9$
\end{tabular}

Source [3]

Table 3: Thermophysical properties of air at $29.7^{\circ} \mathrm{C}$, $1 \mathrm{~atm}$ used for the study.

\begin{tabular}{ll}
\hline Properties & Value \\
\hline Thermal conductivity & $0.02588 \mathrm{Wm}^{-1} \mathrm{~K}^{-1}$ \\
Specific heat capacity & $1007 \mathrm{KJ} \mathrm{kg}^{-1} \mathrm{~K}^{-1}$ \\
Dynamic viscosity & $1.872 \times 10-5 \mathrm{kgm}^{-1} \mathrm{~s}^{-1}$ \\
Prandtl number & 0.7282 \\
\hline
\end{tabular}

\section{NUMERICAL MODELLING APPROACH}

A combination of the explicit-first order finite difference (FDM) and the effective heat capacity (EHC) methods were adopted as numerical methods used in discretizing and solving the PCM model equations. While the HDPE equations were discretised using FDM method. Assumptions used to simplify the analysis are as follows:

1. Ambient air, Paraffin wax and HDPE shell temperature varies along the radial direction of each PCM capsule; $T_{f}=T_{f}(r), T_{w}=T_{w}(r)$ and $T_{p}$ $=T_{p}(r)$.

2. One dimensional transient state is considered for the paraffin wax and HDPE shell hence; $\partial \mathrm{T} / \partial \theta=$ $0, \partial \mathrm{T} / \partial \emptyset=0, \partial \mathrm{T} / \partial \mathrm{t} \neq 0$

3. No internal heat generation in the PCM capsules; $\emptyset=0$.

4. The PCM regime inside the HDPE capsule is assumed to be solid dominated, therefore the convective heat transfer during phase change in the solid-liquid or liquid-solid interface is neglected.

5. The HDPE-PCM capsules are exposed to air flowing through high pressure axial flow fans at varying ambient temperatures with constant speed of 500rpm.

6. The densities of the HDPE shells and paraffin wax are constant.
7. The momentum equations for the air flow into the HDPE-PCM panel medium are negligible, hence air flow is a function of temperature only.

8. Radiant heat transfer between the capsules is negligible.

9. Thermophysical properties of HDPE shells and paraffin wax do not vary with time.

10. Thermophysical properties of the inlet ambient air into the HDPE-PCM panel medium is constant at an average temperature of the highest daily temperature values.

11. The sides of HDPE-PCM panel medium is externally well insulated with Expended Polystyrene (EPS) board, therefore heat loss from the panel medium system is negligible.

12. The PCM discharge/solidification numerical algorithms are not coupled with the air flow temperature function, hence the heat discharge effects from PCM is shielded from the air flow throughout HDPE-PCM panel unit.

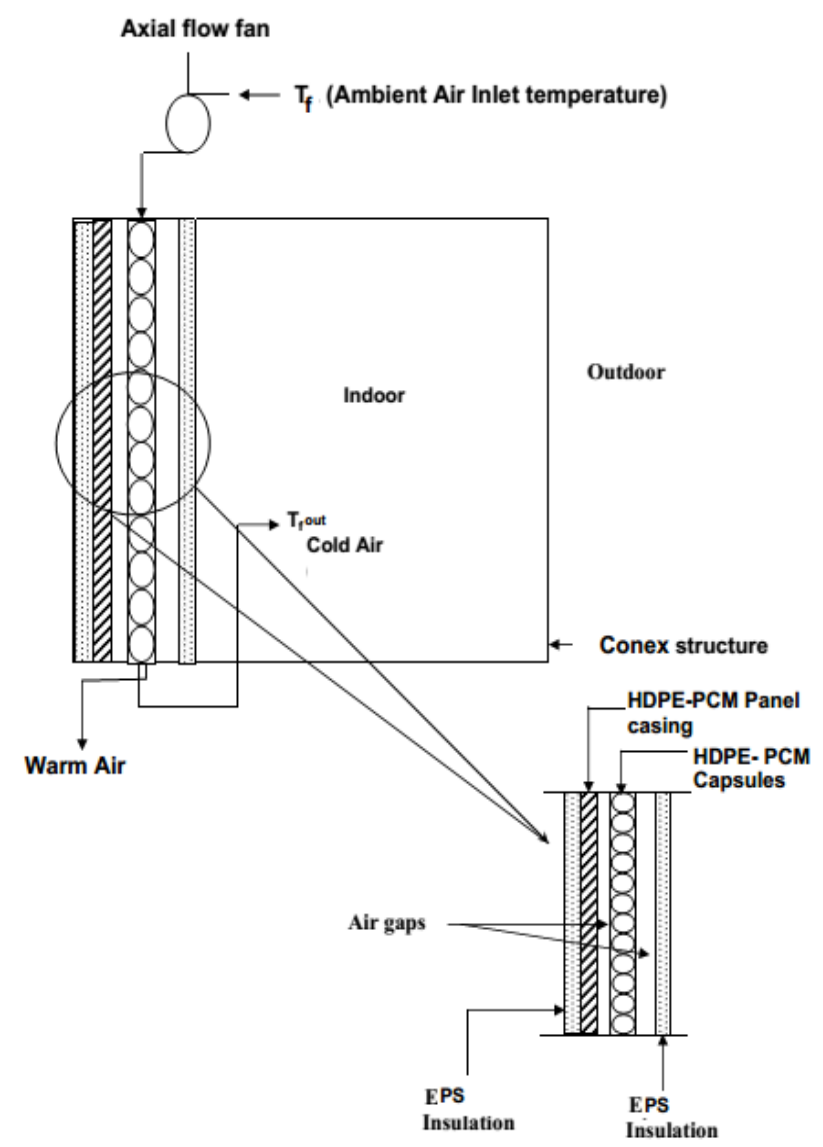

Figure.3: Schematic of the air flow in the axial direction of the HDPE-PCM System, Source: [16]

\subsection{Governing Equations}

To solve the Airflow and HDPE-PCM simulation problem, the above stated assumptions are considered 
hence, a one-dimensional heat model is developed for the PCM used in this study for selected nodes $0-43$. In the same way, the mathematical models for the AirHDPE material interaction is derived as follows:

\subsubsection{Energy balance analysis about HDPE-PCM capsule outer node 0}

The rate of heat transfer by the outdoor air to the HDPE material at the panel inlet capsules node 0 within the control volume is described mathematical as the sum of the heat transfer by convection from ambient air flowing from the axial fan to node 0 and heat transfer by conduction from node 1 to node 0 within control volume equals the rate at which the HDPE material temperature raises at node 0 within the control volume due to energy accumulation at node 0 .

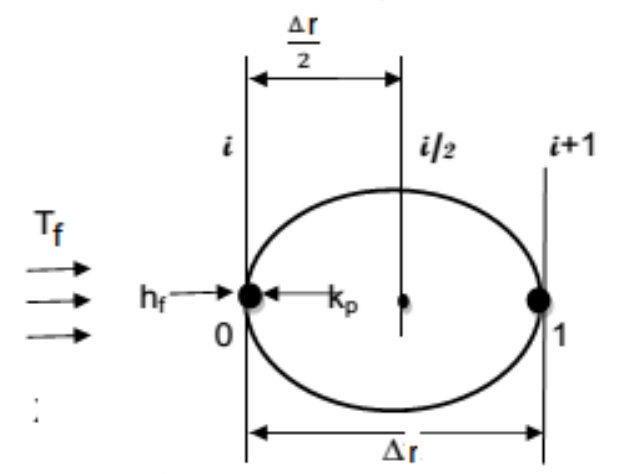

Figure 4: Energy balance analysis about node O(first row/inlet capsules) of the HDPE-PCM panel,

Source: [16]

The governing equation is thus written for nodes 0 and 44 in equation (1).

$$
\begin{aligned}
\ell_{\mathrm{p}} \mathrm{C}_{\mathrm{pp}} \mathrm{A}_{\mathrm{s}} \frac{\partial \mathrm{r}}{2} \frac{\partial \mathrm{T}_{\mathrm{p}}}{\partial \mathrm{t}} & =\frac{\mathrm{k}_{\mathrm{p}}}{\mathrm{r}^{2}} \mathrm{~A}_{\mathrm{s}} \frac{\partial}{\partial \mathrm{r}} \frac{\mathrm{r}^{2} \partial\left(\mathrm{T}_{\mathrm{p}_{1}}-\mathrm{T}_{\mathrm{p} 0}\right)}{\partial \mathrm{r}} \\
& +\mathrm{h}_{\mathrm{f}} \mathrm{A}_{\mathrm{s}}\left(\mathrm{T}_{\mathrm{f} 0}-\mathrm{T}_{\mathrm{p} 0}\right)
\end{aligned}
$$

Equation (1) can be written as

$$
\begin{aligned}
\ell_{\mathrm{p}} \mathrm{C}_{\mathrm{pp}} \mathrm{A}_{\mathrm{s}} \frac{\partial \mathrm{r}}{2} \frac{\partial \mathrm{T}_{\mathrm{p}}}{\partial \mathrm{t}}= & \frac{\mathrm{k}_{\mathrm{p}}}{\mathrm{r}} \mathrm{A}_{\mathrm{s}} \frac{\partial^{2}\left(\mathrm{r}\left(T_{p_{1}}-\mathrm{T}_{\mathrm{p} 0}\right)\right)}{\partial \mathrm{r}^{2}} \\
& +\mathrm{h}_{\mathrm{f}} \mathrm{A}_{\mathrm{s}}\left(\mathrm{T}_{\mathrm{f} 0}-\mathrm{T}_{\mathrm{p} 0}\right)
\end{aligned}
$$

Initial Conditions:

$$
\begin{array}{r}
\mathrm{T}_{\mathrm{f}(\mathrm{r}, 0)}=\mathrm{T}_{\mathrm{f} \text { in }} \\
\mathrm{T}_{\mathrm{p}\left(\mathrm{r}_{0}, 0\right)}=\mathrm{T}_{\mathrm{p} \text { intial }}
\end{array}
$$

Boundary Conditions:

$$
\begin{array}{r}
\mathrm{T}_{\mathrm{f}(\mathrm{r}, \mathrm{t})}=-\frac{\mathrm{h}_{\mathrm{f}}}{\mathrm{k}_{\mathrm{p}}}\left[\mathrm{T}_{\mathrm{p}(\mathrm{r}, \mathrm{t})}-\mathrm{T}_{\mathrm{f}(\mathrm{r}, \mathrm{t})}\right] \\
\mathrm{T}_{\mathrm{p}\left(\mathrm{r}_{0}, \mathrm{t}\right)}=-\mathrm{k}_{\mathrm{p}}\left[\mathrm{T}_{\mathrm{p}\left(\mathrm{r}_{2}, \mathrm{t}\right)}-\mathrm{T}_{\mathrm{p}\left(\mathrm{r}_{1}, \mathrm{t}\right)}\right]
\end{array}
$$

To simplify the governing equation (1) for a suitable numerical approach implementation, the following applicable dimensionless parameters ae defined. $r^{*}=\frac{r}{r_{h}}, \tau^{*}=\frac{t}{t_{0}}, \theta=\frac{T-T_{p}}{T_{f}-T_{p}}$
Let $\mathrm{T}_{\mathrm{p}}=\mathrm{T}_{\mathrm{p} 1}-\mathrm{T}_{\mathrm{p} 0}$ in equation (1) for simplicity thus substituting the dimensionless parameters into equation (1) gives

$$
\begin{aligned}
\ell_{\mathrm{p}} \mathrm{C}_{\mathrm{pp}} \mathrm{A}_{\mathrm{s}} \mathrm{t}_{0} \frac{\left(\mathrm{r}^{*} \mathrm{r}_{\mathrm{h}}\right)^{2}}{2} & \frac{\partial \mathrm{T}_{\mathrm{p}}}{\partial \tau^{*}} \\
& =\mathrm{k}_{\mathrm{p}} \mathrm{A}_{\mathrm{s}} \mathrm{t}_{0} \frac{\partial\left(\mathrm{T}-\mathrm{T}_{\mathrm{p}}\right)+\mathrm{T}_{\mathrm{f}}}{\partial \mathrm{r}^{*} \partial \theta} \\
& +\mathrm{A}_{\mathrm{s}} \frac{\mathrm{h}_{\mathrm{f}}}{\mathrm{k}_{\mathrm{p}}}\left(\mathrm{T}_{\mathrm{f} 0}-\mathrm{T}_{\mathrm{p} 0}\right)
\end{aligned}
$$

Dividing through by $A_{s} t_{0} r^{*} r_{h}$ gives

$$
\begin{aligned}
\ell_{\mathrm{p}} \mathrm{C}_{\mathrm{pp}} \frac{\mathrm{r}^{*} \mathrm{r}_{\mathrm{h}}}{2} \frac{\partial \mathrm{T}_{\mathrm{p}}}{\partial \tau^{*}}= & \frac{\mathrm{k}_{\mathrm{p}}}{\mathrm{r}^{*} \mathrm{r}_{\mathrm{h}}} \frac{\partial\left(\mathrm{T}-\mathrm{T}_{\mathrm{p}}\right)+\mathrm{T}_{\mathrm{f}}}{\partial \mathrm{r}^{*} \partial \theta} \\
& +\frac{\mathrm{h}_{\mathrm{f}}}{\mathrm{t}_{0} \mathrm{r}^{*} \mathrm{r}_{\mathrm{h}} \mathrm{k}_{\mathrm{p}}^{2}}\left(\mathrm{~T}_{\mathrm{f} 0}-\mathrm{T}_{\mathrm{p} 0}\right)
\end{aligned}
$$

Dividing equation (8) by $k_{p}$ and multiplying the solution with $\propto_{\mathrm{p}}=\frac{\mathrm{k}_{\mathrm{p}}}{\ell_{\mathrm{p}} \mathrm{C}_{\mathrm{pp}}}$ gives:

$$
\begin{aligned}
& \frac{\mathrm{r}^{*} \mathrm{r}_{\mathrm{h}}}{2} \frac{\partial \mathrm{T}_{\mathrm{p}}}{\partial \tau^{*}}=\frac{\propto_{\mathrm{p}}}{\mathrm{r}^{*} \mathrm{r}_{\mathrm{h}}} \frac{\partial\left(\mathrm{T}-\mathrm{T}_{\mathrm{p}}\right)+\mathrm{T}_{\mathrm{f}}}{\partial \mathrm{r}^{*} \partial \theta} \\
&+\frac{\alpha_{\mathrm{p}}}{\mathrm{t}_{0} \mathrm{r}^{*} \mathrm{r}_{\mathrm{hk}}} \mathrm{h}_{\mathrm{f}}\left(\mathrm{T}_{\mathrm{f} 0}-\mathrm{T}_{\mathrm{p} 0}\right)
\end{aligned}
$$

By the order of magnitude analysis of equation (9) both terms in the RHS can be compared and viewed to have about the same magnitude hence, no justification to neglect one term in preference to the other, thus both terms in equation (9) are retained. Substituting $\mathrm{T}_{\mathrm{p}}=\mathrm{T}_{\mathrm{p} 1}-\mathrm{T}_{\mathrm{p} 0}$ and $\theta=\frac{\mathrm{T}^{-} \mathrm{T}_{\mathrm{p}}}{\mathrm{T}_{\mathrm{f}}-\mathrm{T}_{\mathrm{p}}}$ back to equation (9) yields

$$
\begin{aligned}
\frac{\mathrm{r}^{*} \mathrm{r}_{\mathrm{h}}}{2} \frac{\partial \mathrm{T}_{\mathrm{p}}}{\partial \tau^{*}}=\frac{\alpha_{\mathrm{p}}}{\mathrm{r}^{*} \mathrm{r}_{\mathrm{h}}} \frac{\partial\left(\mathrm{T}_{\mathrm{p} 1}-\mathrm{T}_{\mathrm{p} 0}\right)}{\partial \mathrm{r}^{*}} & \\
& +\frac{\alpha_{\mathrm{p}}}{\mathrm{t}_{0} \mathrm{r}^{*} \mathrm{r}_{\mathrm{hk}}} \mathrm{h}_{\mathrm{f}}\left(\mathrm{T}_{\mathrm{f} 0}-\mathrm{T}_{\mathrm{p} 0}\right)
\end{aligned}
$$

Multiplying through by $\frac{\mathrm{r}^{*} \mathrm{r}_{\mathrm{h}}}{\alpha_{\mathrm{p}}}$ gives

$$
\frac{\left(\mathrm{r}^{*} \mathrm{r}_{\mathrm{h}}\right)^{2}}{2 \alpha_{\mathrm{p}}} \frac{\partial \mathrm{T}_{\mathrm{p}}}{\partial \tau^{*}}=\frac{\partial\left(\mathrm{T}_{\mathrm{p} 1}-\mathrm{T}_{\mathrm{p} 0}\right)}{\partial \mathrm{r}^{*}}+\frac{\mathrm{h}_{\mathrm{f}}}{\mathrm{t}_{0} \mathrm{k}_{\mathrm{p}}}\left(\mathrm{T}_{\mathrm{f} 0}-\mathrm{T}_{\mathrm{p} 0}\right)
$$

Equation (11) is multiplied by $\alpha_{\mathrm{p}}=\frac{\mathrm{k}_{\mathrm{p}}}{\ell_{\mathrm{p}} \mathrm{C}_{\mathrm{pp}}}$ to yield

$$
\begin{aligned}
\frac{\left(\mathrm{r}^{*} \mathrm{r}_{\mathrm{h}}\right)^{2}}{2} \frac{\partial \mathrm{T}_{\mathrm{p}}}{\partial \tau^{*} \cdot=} & \frac{\mathrm{k}_{\mathrm{p}}}{\ell_{\mathrm{p}} \mathrm{C}_{\mathrm{pp}}} \frac{\partial\left(\mathrm{T}_{\mathrm{p} 1}-\mathrm{T}_{\mathrm{p} 0}\right)}{\partial \mathrm{r}^{*}} \\
& +\frac{\mathrm{h}_{\mathrm{f}}}{\mathrm{t}_{0} \ell_{\mathrm{p}} \mathrm{C}_{\mathrm{pp}}}\left(\mathrm{T}_{\mathrm{f} 0}-\mathrm{T}_{\mathrm{p} 0}\right)
\end{aligned}
$$

Dividing equation (12) by $\frac{\left(r^{*} r_{h}\right)^{2}}{2}$ where $r^{*}=\frac{r}{r_{h}}$, equation (12) becomes

$$
\begin{aligned}
\frac{\partial \mathrm{T}_{\mathrm{p}}}{\partial \tau^{*}}=\frac{2 \mathrm{k}_{\mathrm{p}}}{\ell_{\mathrm{p}} \mathrm{C}_{\mathrm{pp}} r^{2}} & \frac{\partial\left(\mathrm{T}_{\mathrm{p} 1}-\mathrm{T}_{\mathrm{p} 0}\right) r_{h}}{\partial \mathrm{r}} \\
& +\frac{2 \mathrm{~h}_{\mathrm{f}}}{\mathrm{t}_{0} \ell_{\mathrm{p}} \mathrm{C}_{\mathrm{pp}} r^{2}}\left(\mathrm{~T}_{\mathrm{f} 0}-\mathrm{T}_{\mathrm{p} 0}\right)
\end{aligned}
$$

Multiplying through by $\frac{\mathrm{r}^{2}}{2}$ gives 


$$
\begin{aligned}
\frac{\mathrm{r}^{2} \partial \mathrm{T}_{\mathrm{p}}}{2 \partial \tau^{*}}=\frac{\mathrm{k}_{\mathrm{p}}}{\ell_{\mathrm{p}} \mathrm{C}_{\mathrm{pp}}} \frac{\partial\left(\mathrm{T}_{\mathrm{p} 1}-\mathrm{T}_{\mathrm{p} 0}\right) r_{h}}{\partial \mathrm{r}} & \\
& +\frac{\mathrm{t} * \mathrm{~h}_{\mathrm{f}}}{\tau^{*} \ell_{\mathrm{p}} \mathrm{C}_{\mathrm{pp}}}\left(\mathrm{T}_{\mathrm{f} 0}-\mathrm{T}_{\mathrm{p} 0}\right)
\end{aligned}
$$

Discretizing equation (14) using the simple explicit and first order finite difference formulation, gives

$$
\begin{aligned}
\frac{\mathrm{T}_{\mathrm{po}, \mathrm{i}}^{\mathrm{n}+1}-\mathrm{T}_{\mathrm{po}, \mathrm{i}}^{\mathrm{n}}}{2 \Delta \mathrm{t}} \Delta \mathrm{r}^{2} & \\
& =\frac{\mathrm{k}_{\mathrm{p}}}{\ell_{\mathrm{p}} \mathrm{C}_{\mathrm{pp}}} \frac{\mathrm{T}_{\mathrm{p} 1, \mathrm{i}+1}^{\mathrm{n}}-\mathrm{T}_{\mathrm{po}, \mathrm{i}}^{\mathrm{n}}}{\Delta \mathrm{r}} \\
& +\frac{\mathrm{h}_{\mathrm{f}}}{\ell_{\mathrm{p}} \mathrm{C}_{\mathrm{pp}}} \frac{\mathrm{T}_{\mathrm{fo}}^{\mathrm{n}}-\mathrm{T}_{\mathrm{po}, \mathrm{i}}^{\mathrm{n}}}{\Delta \mathrm{t}}
\end{aligned}
$$

Multiplying equation (15) by $\frac{2 \Delta t}{\Delta \mathrm{r}^{2}}$, having that $\alpha_{\mathrm{p}}=$ $\frac{\mathrm{k}_{\mathrm{p}}}{\ell_{\mathrm{p}} \mathrm{C}_{\mathrm{pp}}}$ gives

$$
\begin{aligned}
\mathrm{T}_{\mathrm{po}, \mathrm{i}}^{\mathrm{n}+1}=\frac{\alpha_{\mathrm{p}} 2 \mathrm{~h}_{\mathrm{f}}}{\mathrm{k}_{\mathrm{p}} \Delta \mathrm{r}^{2}} & \left(\mathrm{~T}_{\mathrm{fo}, \mathrm{i}}^{\mathrm{n}}-\mathrm{T}_{\mathrm{po}, \mathrm{i}}^{\mathrm{n}}\right) \\
& +\frac{2 \Delta \mathrm{t} \alpha_{\mathrm{p}}}{\Delta \mathrm{r}^{3}}\left(\mathrm{~T}_{\mathrm{p} 1, \mathrm{i}+1}^{\mathrm{n}}-\mathrm{T}_{\mathrm{po}, \mathrm{i}}^{\mathrm{n}}\right) \\
& +\mathrm{T}_{\mathrm{po}, \mathrm{i}}^{\mathrm{n}}
\end{aligned}
$$

Recognizing that $\mathrm{F}_{\mathrm{o}}=\frac{\alpha_{\mathrm{p}} \Delta \mathrm{t}}{\Delta \mathrm{r}^{2}}$, hence

$$
\begin{gathered}
\mathrm{T}_{\mathrm{po}, \mathrm{i}}^{\mathrm{n}+1}=2 \mathrm{~F}_{\mathrm{o}} \frac{\mathrm{h}_{\mathrm{f}}}{\Delta \mathrm{t}}\left(\mathrm{T}_{\mathrm{fo}, \mathrm{i}}^{\mathrm{n}}-\mathrm{T}_{\mathrm{po}, \mathrm{i}}^{\mathrm{n}}\right)+\frac{2 \mathrm{~F}_{\mathrm{o}}}{\Delta \mathrm{r}}\left(\mathrm{T}_{\mathrm{p} 1, \mathrm{i}+1}^{\mathrm{n}}-\mathrm{T}_{\mathrm{po}, \mathrm{i}}^{\mathrm{n}}\right) \\
+\mathrm{T}_{\mathrm{po}, \mathrm{i}}^{\mathrm{n}}
\end{gathered}
$$

Equation (18-25) were used to determine the convective heat transfer coefficient of the ambient air flowing throughout the HDPE-PCM panel unit at steady state. The temperature performances of both the flowing air and the HDPE capsule material are solely dependent on the operation of the PCM. Hence, to determine the value for the computational time $\Delta t$ in equation (17), a stability criterion analysis of the Paraffin wax is performed in equation (88).

$$
\mathrm{h}_{\mathrm{f}}=\frac{\mathrm{Nu} \times \mathrm{k}_{\mathrm{f}}}{\mu_{\mathrm{f}}}
$$

$\mathrm{Nu}=7.541+\left(\frac{0.02(1-\varepsilon)^{0.6} \times \mathrm{Re}^{0.6} \times \mathrm{P}_{\mathrm{r}}}{\mathrm{h}}\right)^{1 / 3}$

Where the Reynolds number, $\operatorname{Re}=\frac{\ell_{\mathrm{f}} * \mathrm{C} * \mathrm{~h}}{\mu_{\mathrm{f}}}, \mathrm{C}=$ $\frac{\mathrm{Q}_{\mathrm{v}}}{\mathrm{A}_{\mathrm{D}}} \& \Delta \mathrm{r}=\frac{\mathrm{h}}{\mathrm{N}_{\mathrm{y}}}$, where $\mathrm{h}=2.65 \mathrm{~m}$ being the HDPE-PCM panel height considered as the length of the axial air flow region, $\mathrm{N}=44$ being the number of capsules arranged in the axial y direction and $\Delta \mathrm{r}=0.06 \mathrm{~m}$ being the outer diameter of each capsule. $A_{D}=1.392 m^{2}$ being the duct area for one axial flow fan, $Q_{V}$ is the volume flow rate of the fan at 500rpm.

Equation (19), was developed by [13] as a correlation to determine the Nusselt number for a forced convection PCM/Air exchange system for building application. In equation (19), the porosity, $\varepsilon=0.9$ of the HDPE-PCM panel is determined using equation (20) developed by [14] for packed capsule systems.

$$
\varepsilon=\frac{\mathrm{V}_{\mathrm{p}}-\mathrm{V}_{\mathrm{o}}}{\mathrm{V}_{\mathrm{p}}}
$$

$\mathrm{V}_{\mathrm{p}}$ is the volume of paraffin wax storage in the HDPE capsules, $V_{o}$ is the volume of the void fraction in the HDPE-PCM panel medium. In determining the volume of the void fraction, equation (21) is used.

$$
\mathrm{V}_{\mathrm{o}}=\frac{\mathrm{A}_{\mathrm{p}}}{\mathrm{A}_{\mathrm{s}}}
$$

$A_{p}=15.9 m^{2}$ being the area of the HDPE-PCM panel medium and $A_{s}=0.0113 \mathrm{~m}^{2}$ being the surface area of each capsule. The determination of $V_{p}$ in equation (20) requires the solutions of equation (22-25).

$$
\mathrm{V}_{\mathrm{p}}=\frac{4}{3} \pi\left(R-\mathrm{t}_{\mathrm{p}}\right)^{3}
$$

Where $R=0.03 \mathrm{~m}$ being the external radius of each HDPE capsule and $t_{p}=0.8 \mathrm{~mm}$ being the thickness of the HDPE shell coating of the capsules.

$$
\mathrm{m}_{\mathrm{s}}=\mathrm{V}_{\mathrm{p}} \times\left(\ell_{\mathrm{w}}+\ell_{\mathrm{p}}\right)
$$

Numerical values for $\ell_{\mathrm{w}} \& \ell_{\mathrm{p}}$ are obtained in tables 1 and 2

$$
\mathrm{m}_{\mathrm{p}}=\mathrm{m}_{\mathrm{s}} \times \mathrm{N}_{\mathrm{c}}
$$

The mass of the entire HDPE-PCM panel is $m_{p}=$ $629.2 \mathrm{~kg}$, while the mass of a single capsule $\mathrm{m}_{\mathrm{s}}=$ $0.143 \mathrm{~kg}$

$$
\mathrm{N}_{\mathrm{c}}=\mathrm{N}_{\mathrm{y}} \times \mathrm{N}_{\mathrm{x}}
$$

$\mathrm{N}_{\mathrm{y}}=44$ being the number of HDPE capsules packed in the $y$-axis (axial flow direction), while $\mathrm{N}_{\mathrm{x}}=100$ being the number of HDPE capsules packed in the $x-$ axis. A total of $\mathrm{N}_{\mathrm{c}}=4,400$ HDPE capsules occupy the panel medium of study. By substituting parameters in tables $1,2 \& 3$ and the solutions of equations (18-25) into equation (17), the numerical values for $\mathrm{F}_{\mathrm{o}}, \mathrm{h}_{\mathrm{f}} \& \Delta \mathrm{r}$ is obtained. Therefore, equation (19) becomes

$$
\begin{gathered}
\mathrm{T}_{\mathrm{po}, \mathrm{i}}^{\mathrm{n}+1}=0.073\left(\mathrm{~T}_{\mathrm{fo}, \mathrm{i}}^{\mathrm{n}}-\mathrm{T}_{\mathrm{po}, \mathrm{i}}^{\mathrm{n}}\right)+16.30\left(\mathrm{~T}_{\mathrm{p} 1, \mathrm{i}+1}^{\mathrm{n}}-\mathrm{T}_{\mathrm{po}, \mathrm{i}}^{\mathrm{n}}\right) \\
+\mathrm{T}_{\mathrm{po}, \mathrm{i}}^{\mathrm{n}}
\end{gathered}
$$

Equation (26) is the numerical algorithm used to predict the temperature fluctuations of nodes 0 and 44 only and can be written for new time steps forming a system of $\mathrm{N}$-algebraic linear equations as follows;

$$
\begin{aligned}
& \mathrm{T}_{\mathrm{po}, \mathrm{i}}^{\mathrm{n}+1}=16.30\left(\mathrm{~T}_{\mathrm{P} 1, \mathrm{i}+1}^{\mathrm{n}}+4.47 \times 10^{-3} \mathrm{~T}_{\mathrm{fo}, \mathrm{i}}^{\mathrm{n}}\right)-15.37 \mathrm{~T}_{\mathrm{Po}, \mathrm{i}}^{\mathrm{n}} \\
& \mathrm{T}_{\mathrm{Po}, \mathrm{I}}^{\mathrm{n}+2}=16.30\left(\mathrm{~T}_{\mathrm{P} 1, \mathrm{i}+1}^{\mathrm{n}+1}+4.47 \times 10^{-3} \mathrm{~T}_{\mathrm{fo}, \mathrm{i}}^{\mathrm{n}+1}\right)- \\
& 15.37 \mathrm{~T}_{\mathrm{Po}, \mathrm{i}}^{\mathrm{n}+1} \\
& \mathrm{~T}_{\mathrm{Po}, \mathrm{i}}^{\mathrm{n}+\infty}=16.30\left(\mathrm{~T}_{\mathrm{P} 1, \mathrm{i}+1}^{\mathrm{n}+(\infty-1)}+4.47 \times 10^{-3} \mathrm{~T}_{\mathrm{fo}, \mathrm{i}}^{\mathrm{n}+(\infty-1)}\right)- \\
& 15.37 \mathrm{~T}_{\mathrm{Po}, \mathrm{i}}^{\mathrm{n}+(\infty-1)}
\end{aligned}
$$




\subsubsection{Determination of HDPE shell surface nodal temperatures at first iteration time step, $T_{P o, i}^{n}$}

The HDPE capsule surface node temperature accounts for the temperature distribution across discrete nodes on each capsule surface without any physical interaction with the PCM as a result of energy transferred by ambient air to the HDPE material. Therefore, the governing equation for surface nodes (1-44) at first time step can be derived from the surface energy balance given below applicable at steady-state conditions neglecting radiant heat transfer.

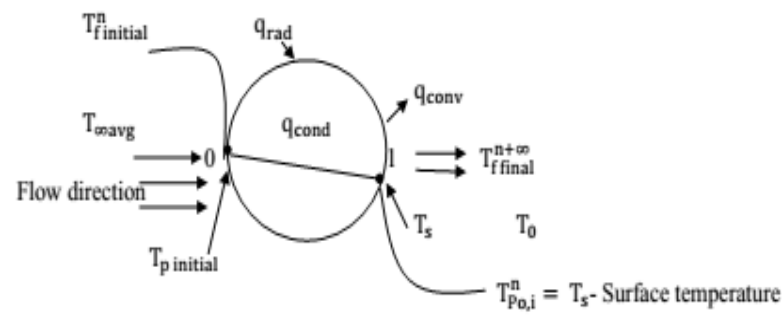

Figure 5: Energy balance analysis about HDPE shell surface temperature for nodes 0 - 44 at steady state, Source: [16]

$$
\begin{gathered}
\mathrm{q}_{\text {cond }}=\mathrm{q}_{\mathrm{conv}}+\mathrm{q}_{\mathrm{rad}} \\
\mathrm{q}_{\text {cond }}=\mathrm{k}_{\mathrm{p}} \mathrm{A}_{\mathrm{pt}} \frac{\mathrm{T}_{\infty}^{\mathrm{n}}-\mathrm{T}_{\mathrm{s}}}{\mathrm{h}} \\
\mathrm{q}_{\text {conv }}=\mathrm{h}_{\mathrm{f}} \mathrm{A}_{\mathrm{pt}} \Delta \mathrm{T}_{\mathrm{lm}} \\
\mathrm{q}_{\mathrm{rad}}=\epsilon \sigma\left(\mathrm{T}_{\mathrm{s}}^{4}-\mathrm{T}_{\infty}^{4}\right)
\end{gathered}
$$

Where $\epsilon$ is the emissivity of HDPE shell between $(0.8$ - 0.9), and 6 is the Stefan Boltzmann Constant $\left(5.67 * 10^{-8} \mathrm{~W} / \mathrm{m}^{2} \mathrm{~K}^{4}\right)$. The unknown is $\mathrm{T}_{\mathrm{s}}$ (surface Node temperature) and cannot be solved explicitly because of the fourth power dependence of the radiation term. Therefore the radiation heat flux $\mathrm{q}_{\mathrm{rad}}$ can be written in terms of the radiation heat transfer coefficient as in equation (30). By Substituting equations $(28-30)$ into equation (29) gives:

$$
\mathrm{k}_{\mathrm{p}} \mathrm{A}_{\mathrm{pt}} \frac{\mathrm{T}_{\infty}^{\mathrm{n}}-\mathrm{T}_{\mathrm{s}}}{\mathrm{h}}=\mathrm{h}_{\mathrm{f}} \mathrm{A}_{\mathrm{pt}} \Delta \mathrm{T}_{\mathrm{Im}}+\mathrm{h}_{\mathrm{r}}\left(\mathrm{T}_{\mathrm{r}}-\mathrm{T}_{\infty}\right)
$$

Based on the assumptions, the radiative heat transfer coefficient $h_{r}$ within the capsules is negligible. Therefore, the surface nodal energy balance equation (31) is reduced to (32):

$$
\mathrm{k}_{\mathrm{p}} \mathrm{A}_{\mathrm{pt}} \frac{\mathrm{T}_{\infty}^{\mathrm{n}}-\mathrm{T}_{\mathrm{s}}}{\mathrm{h}}=\mathrm{h}_{\mathrm{f}} \mathrm{A}_{\mathrm{pt}} \Delta \mathrm{T}_{\mathrm{Im}}
$$

Where $\Delta T_{\text {im }}$ is the log-mean temperature difference, $A_{p t}$ is the surface area of all the capsules in the panel medium given by $A_{p t}=A_{p} * \varepsilon$ and $T_{\infty}^{n}$ is the ambient temperature at first iteration time step -12am for the hottest of simulation day 1-4.

$$
\Delta \mathrm{T}_{\mathrm{lm}}=\frac{\left(\mathrm{T}_{\text {pinitial }}-\mathrm{T}_{\infty \text { mid }}\right)-\left(\mathrm{T}_{\text {pinitial }}-\mathrm{T}_{\mathrm{o}}\right)}{\operatorname{In}\left(\frac{\mathrm{T}_{\text {pinitial }}-\mathrm{T}_{\infty \text { omid }}}{\mathrm{T}_{\text {pinitial }}-\mathrm{T}_{\mathrm{o}}}\right)}
$$

The log-mean temperature difference $\Delta \mathrm{T}_{\mathrm{Im}}$ developed by [15] where $\mathrm{T}_{\infty \text { mid }}$ is the mid-daytime ambient temperature, $T_{\text {pinitial }}$ is the initial HDPE-PCM panel temperature, $T_{0}$ is the estimated outlet temperature. In determining the value of estimated outlet temperature $T_{0}$, the expression below by [15] is adopted to so that the log-mean temperature difference $\Delta \mathrm{T}_{\mathrm{im}}=0.011^{\circ} \mathrm{C}$.

$$
\frac{\mathrm{T}_{\text {pinitial }}-\mathrm{T}_{\mathrm{o}}}{\mathrm{T}_{\text {pinitial }}-\mathrm{T}_{\infty \mathrm{mid}}}=\exp \left(-\frac{\mathrm{h}_{\mathrm{f}} \mathrm{A}_{\mathrm{pt}}}{\ell_{\mathrm{f}} \times \mathrm{C} \times \mathrm{A}_{\mathrm{p}} \times \mathrm{C}_{\mathrm{pf}}}\right)
$$

Rearranging equation (32) in terms of $\mathrm{q}_{\text {conv }}$ yields

$$
\mathrm{k}_{\mathrm{p}} \mathrm{A}_{\mathrm{pt}} \frac{\mathrm{T}_{\infty}^{\mathrm{n}}-\mathrm{T}_{\mathrm{s}}}{\mathrm{h}}=\mathrm{q}_{\mathrm{conv}}
$$

Taking $\mathrm{T}_{\mathrm{s}}=\mathrm{T}_{\mathrm{po}, \mathrm{i}}^{\mathrm{n}}$ and $\mathrm{T}_{\infty}^{\mathrm{n}}=\mathrm{T}_{\mathrm{fo}, \mathrm{i}}^{\mathrm{n}}=29.0^{\circ} \mathrm{C}$ (Average ambient temperature for day 1-4), hence equation (35) becomes

$$
\begin{gathered}
\mathrm{T}_{\mathrm{po}, \mathrm{i}}^{\mathrm{n}}=\mathrm{T}_{\mathrm{fo}, \mathrm{i}}^{\mathrm{n}}-\frac{\mathrm{r} \times \mathrm{q}_{\mathrm{conv}}}{\mathrm{A}_{\mathrm{pt}} \times \mathrm{k}_{\mathrm{p}}} \\
\mathrm{T}_{\mathrm{p}}^{\mathrm{n}}\left(\mathrm{r}_{0}\right)=\frac{\mathrm{x}^{2}}{2 \mathrm{k}_{\mathrm{p}}}\left(1-\frac{\mathrm{x}^{2}}{\mathrm{~h}^{2}}\right)+\mathrm{T}_{\mathrm{po}, \mathrm{i}}^{\mathrm{n}} ; r_{0}=\Delta \mathrm{h} \pm 0.06 \mathrm{~m}
\end{gathered}
$$

Where $r_{0}$ is the nodal increment along HDPE-PCM panel height for nodes 0-44.Equation (37) is written for first iteration time(12am) for day 1-4 as presented in equations $(38-41)$. All ambient temperature data were obtained using the Arduino Uno and type $K$ thermocouple sensors.

Day 1:

$$
\mathrm{T}_{\mathrm{p}}^{\mathrm{n}}(\mathrm{r})=0.021\left(1-\frac{\mathrm{x}^{2}}{\mathrm{~h}^{2}}\right)+20.99^{\circ} \mathrm{C}
$$

Day 2:

$$
\mathrm{T}_{\mathrm{p}}^{\mathrm{n}}(\mathrm{r})=0.021\left(1-\frac{\mathrm{x}^{2}}{\mathrm{~h}^{2}}\right)+22.99^{\circ} \mathrm{C}
$$

Day 3:

Day 4:

$$
\mathrm{T}_{\mathrm{p}}^{\mathrm{n}}(r)=0.021\left(1-\frac{\mathrm{x}^{2}}{\mathrm{~h}^{2}}\right)+24.29^{\circ} \mathrm{C}
$$

$$
\mathrm{T}_{\mathrm{p}}^{\mathrm{n}}(\mathrm{r})=0.021\left(1-\frac{\mathrm{x}^{2}}{\mathrm{~h}^{2}}\right)+23.79^{\circ} \mathrm{C}
$$

Equations (38 - 41) can be solved using MATLAB to derive numerical temperature results for panel nodes 0 - 44 for first iteration time step.

The Energy balance analysis about PCM is the sum of heat quantity transferred by conduction from node 1 to node 2 across capsule space $\Delta r$ and heat transfer by conduction from node 3 to node 2 across capsule space $\Delta r$ equals rise in temperature at node 2 within 
the control volume $\mathrm{A}_{\mathrm{s}} \Delta \mathrm{r}$ due to energy accumulation at node 2 [11].

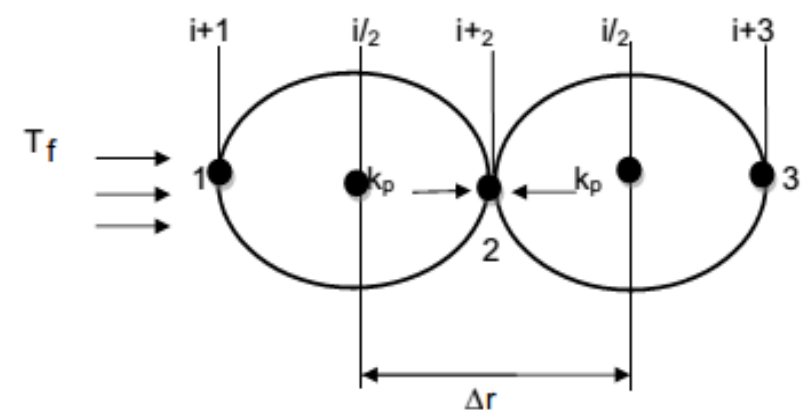

Figure 6: Energy balance analysis about internal nodes $1-43$ of the HDPE-PCM capsules,

Source: [16]

The governing equation for HDPE-PCM internal nodes 1-43 can be written following the energy balance technique and yields

$$
\begin{aligned}
\ell_{\mathrm{p}} \mathrm{C}_{\mathrm{pp}} \mathrm{A}_{\mathrm{s}} \frac{\partial \mathrm{T}_{\mathrm{p}}}{\partial \mathrm{t}}=\varnothing & +\frac{\mathrm{k}_{\mathrm{p}}}{\mathrm{r}^{2}} \mathrm{~A}_{\mathrm{s}} \frac{\partial}{\partial \mathrm{r}} \frac{\mathrm{r}^{2} \partial\left(\mathrm{T}_{\mathrm{p}_{1}}-\mathrm{T}_{\mathrm{p} 2}\right)}{\partial \mathrm{r}} \\
& +\frac{\mathrm{k}_{\mathrm{p}}}{\mathrm{r}^{2}} \mathrm{~A}_{\mathrm{s}} \frac{\partial}{\partial \mathrm{r}} \frac{\mathrm{r}^{2} \partial\left(\mathrm{T}_{\mathrm{p}_{2}}-\mathrm{T}_{\mathrm{p} 3}\right)}{\partial \mathrm{r}}
\end{aligned}
$$

Applying assumption three reduces equation (42) to give

$$
\begin{aligned}
\ell_{\mathrm{p}} \mathrm{C}_{\mathrm{pp}} \mathrm{A}_{\mathrm{s}} \frac{\partial \mathrm{T}_{\mathrm{p}}}{\partial \mathrm{t}}=\frac{\mathrm{k}_{\mathrm{p}}}{\mathrm{r}} \mathrm{A}_{\mathrm{s}} \frac{\partial^{2}\left(\mathrm{r}\left(T_{p_{1}}-\mathrm{T}_{\mathrm{p} 2}\right)\right)}{\partial \mathrm{r}^{2}} \\
+\frac{\mathrm{k}_{\mathrm{p}}}{\mathrm{r}} \mathrm{A}_{\mathrm{s}} \frac{\partial^{2}\left(\mathrm{r}\left(\mathrm{T}_{\mathrm{p}_{2}}-\mathrm{T}_{\mathrm{p} 3}\right)\right)}{\partial \mathrm{r}^{2}}
\end{aligned}
$$

Initial Conditions:

HDPE shell;

$$
\begin{aligned}
& \mathrm{T}_{\mathrm{p}\left(\mathrm{r}_{\mathrm{h}}, 0\right)}=\mathrm{T}_{\mathrm{w}_{\text {initial }}}=\mathrm{T}_{\mathrm{p} \text { initial }} \\
& \mathrm{T}_{\mathrm{p}\left(\mathrm{r}_{0}, 0\right)}=\mathrm{T}_{\mathrm{w}_{\text {inital }}}=\mathrm{T}_{\mathrm{p} \text { intial }}
\end{aligned}
$$

Boundary Conditions:

$$
\begin{gathered}
T_{p\left(r_{0}, t\right)}=-k_{p}\left[T_{p\left(r_{2}, t\right)}-T_{p\left(r_{1}, t\right)}\right] \\
T_{p\left(r_{h}, t\right)}=-k_{p}\left[T_{p\left(r_{h}, t\right)}-T_{p\left(r_{43}, t\right)}\right]
\end{gathered}
$$

To simplify the governing equation (43) for numerical approach, we define the following applicable dimensionless parameters.

$$
r^{*}=\frac{r}{r_{h}}, \tau^{*}=\frac{t}{t_{0}}, \theta=\frac{T-T_{p}}{T_{p}-T_{p+1}}
$$

Let $\mathrm{T}_{\mathrm{p}}=\mathrm{T}_{\mathrm{p} 1}-\mathrm{T}_{\mathrm{p} 2}$ and $\mathrm{T}_{\mathrm{p}+1}=\mathrm{T}_{\mathrm{p} 2}-\mathrm{T}_{\mathrm{p} 3}$ in equation (43) for simplicity thus substituting the dimensionless parameters into equation (43) gives

$$
\begin{aligned}
& \ell_{\mathrm{p}} \mathrm{C}_{\mathrm{pp}} \mathrm{A}_{\mathrm{s}} \mathrm{t}_{0} \mathrm{r}^{*} \mathrm{r}_{\mathrm{h}} \frac{\partial \mathrm{T}_{\mathrm{p}}}{\partial \tau^{*}} \\
& =\mathrm{k}_{\mathrm{p}} \mathrm{A}_{\mathrm{s}} \mathrm{t}_{0} \frac{\partial\left(\mathrm{T}-\mathrm{T}_{\mathrm{p}+1}\right)+\mathrm{T}_{\mathrm{p}}}{\partial \mathrm{r}^{*} \partial \theta} \\
& +\mathrm{k}_{\mathrm{p}} \mathrm{A}_{\mathrm{s}} \mathrm{t}_{0} \mathrm{r}^{*} \mathrm{r}_{\mathrm{h}} \frac{\partial\left(\mathrm{T}-\mathrm{T}_{\mathrm{p}}\right)+\mathrm{T}_{\mathrm{p}}}{\partial \mathrm{r}^{*} \partial \theta}
\end{aligned}
$$

$$
\begin{aligned}
& \ell_{\mathrm{p}} \mathrm{C}_{\mathrm{pp}} \frac{\partial \mathrm{T}_{\mathrm{p}}}{\partial \tau^{*}}=\frac{\mathrm{k}_{\mathrm{p}}}{\mathrm{r}^{*} \mathrm{r}_{\mathrm{h}}} \frac{\partial\left(\mathrm{T}-\mathrm{T}_{\mathrm{p}+1}\right)+\mathrm{T}_{\mathrm{p}}}{\partial \mathrm{r}^{*} \partial \theta} \\
&+\frac{\mathrm{k}_{\mathrm{p}}}{\mathrm{r}^{*} \mathrm{r}_{\mathrm{h}}} \frac{\partial\left(\mathrm{T}-\mathrm{T}_{\mathrm{p}}\right)+\mathrm{T}_{\mathrm{p}}}{\partial \mathrm{r}^{*} \partial \theta}
\end{aligned}
$$

Dividing equation (49) through by $\mathrm{k}_{\mathrm{p}}$ and multiplying the solution by $\propto_{\mathrm{p}}=\frac{\mathrm{k}_{\mathrm{p}}}{\ell_{\mathrm{p}} \mathrm{C}_{\mathrm{pp}}}$ gives:

$$
\begin{aligned}
\frac{\partial \mathrm{T}_{\mathrm{p}}}{\partial \tau^{*}}=\frac{\alpha_{\mathrm{p}}}{\mathrm{r}^{*} \mathrm{r}_{\mathrm{h}} \frac{\partial\left(\mathrm{T}-\mathrm{T}_{\mathrm{p}+1}\right)+\mathrm{T}_{\mathrm{p}}}{\partial \mathrm{r}^{*} \partial \theta}} \\
+\frac{\alpha_{\mathrm{p}}}{\mathrm{r}^{*} \mathrm{r}_{\mathrm{h}}} \frac{\partial\left(\mathrm{T}-\mathrm{T}_{\mathrm{p}}\right)+\mathrm{T}_{\mathrm{p}}}{\partial \mathrm{r}^{*} \partial \theta}
\end{aligned}
$$

In applying the order of magnitude analysis on equation (50), both terms in the RHS are compared to have about the same magnitude, hence there is no justification to neglect one in preference to the other, hence both terms are retained. Substituting $\mathrm{T}_{\mathrm{p}}=\mathrm{T}_{\mathrm{p} 1}$ $\mathrm{T}_{\mathrm{p} 2}$ and $\mathrm{T}_{\mathrm{p}+1}=\mathrm{T}_{\mathrm{p} 2}-\mathrm{T}_{\mathrm{p} 3}$ and $\theta=\frac{\mathrm{T}-\mathrm{T}_{\mathrm{p}}}{\mathrm{T}_{\mathrm{p}}-\mathrm{T}_{\mathrm{p}+1}}$ back to equation (50) yields

$$
\begin{aligned}
\frac{\partial \mathrm{T}_{\mathrm{p}}}{\partial \tau^{*}}=\frac{\alpha_{\mathrm{p}}}{\mathrm{r}^{*} \mathrm{r}_{\mathrm{h}}} \frac{\partial\left(\mathrm{T}_{\mathrm{p} 1}-\mathrm{T}_{\mathrm{p} 2}\right)}{\partial \mathrm{r}^{*}} & \\
& +\frac{\alpha_{\mathrm{p}}}{\mathrm{r}^{*} \mathrm{r}_{\mathrm{h}}} \frac{\partial\left(\mathrm{T}_{\mathrm{p} 2}-\mathrm{T}_{\mathrm{p} 3}\right)}{\partial \mathrm{r}^{*}}
\end{aligned}
$$

Multiplying through by $\frac{r^{*} r_{h}}{\alpha_{p}}$ gives

$$
\frac{\mathrm{r}^{*} \mathrm{r}_{\mathrm{h}}}{\alpha_{\mathrm{p}}} \frac{\partial \mathrm{T}_{\mathrm{p}}}{\partial \tau^{*}}=\frac{\partial\left(\mathrm{T}_{\mathrm{p} 1}-\mathrm{T}_{\mathrm{p} 2}\right)}{\partial \mathrm{r}^{*}}+\frac{\partial\left(\mathrm{T}_{\mathrm{p} 2}-\mathrm{T}_{\mathrm{p} 3}\right)}{\partial \mathrm{r}^{*}}
$$

Equation (52) is multiplied by $\alpha_{\mathrm{p}}=\frac{\mathrm{k}_{\mathrm{p}}}{\ell_{\mathrm{p}} \mathrm{C}_{\mathrm{pp}}}$ to yield

$$
\begin{aligned}
& \mathrm{r}^{*} \mathrm{r}_{\mathrm{h}} \frac{\partial \mathrm{T}_{\mathrm{p}}}{\partial \tau^{*} \cdot}=\frac{\mathrm{k}_{\mathrm{p}}}{\ell_{\mathrm{p}} \mathrm{C}_{\mathrm{pp}}} \frac{\partial\left(\mathrm{T}_{\mathrm{p} 1}-\mathrm{T}_{\mathrm{p} 2}\right)}{\partial \mathrm{r}^{*}} \\
& +\frac{\mathrm{k}_{\mathrm{p}}}{\ell_{\mathrm{p}} \mathrm{C}_{\mathrm{pp}}} \frac{\partial\left(\mathrm{T}_{\mathrm{p} 2}-\mathrm{T}_{\mathrm{p} 3}\right)}{\partial \mathrm{r}^{*}}
\end{aligned}
$$

Rearranging equation (53) gives

$\frac{\mathrm{k}_{\mathrm{p}} \mathrm{r}_{\mathrm{h}}}{\ell_{\mathrm{p}} \mathrm{C}_{\mathrm{pp}}} \frac{\partial\left(\mathrm{T}_{\mathrm{p} 1}-\mathrm{T}_{\mathrm{p} 2}\right)}{\partial \mathrm{r}}+\frac{\mathrm{k}_{\mathrm{p}} \mathrm{r}_{\mathrm{h}}}{\ell_{\mathrm{p}} \mathrm{C}_{\mathrm{pp}}} \frac{\partial\left(\mathrm{T}_{\mathrm{p} 2}-\mathrm{T}_{\mathrm{p} 3}\right)}{\partial \mathrm{r}}=\mathrm{r}^{*} \mathrm{r}_{\mathrm{h}}$

Multiplying equation (54) by $\frac{\ell_{\mathrm{p}} \mathrm{C}_{\mathrm{pp}}}{r_{h} \mathrm{k}_{\mathrm{p}}}$ gives

$$
\frac{\partial\left(\mathrm{T}_{\mathrm{p} 1}-\mathrm{T}_{\mathrm{p} 2}\right)}{\partial \mathrm{r}}+\frac{\partial\left(\mathrm{T}_{\mathrm{p} 2}-\mathrm{T}_{\mathrm{p} 3}\right)}{\partial \mathrm{r}}=\frac{\ell_{\mathrm{p}} \mathrm{C}_{\mathrm{pp}} \mathrm{r}^{*}}{\mathrm{k}_{\mathrm{p}}} \cdot \frac{\partial \mathrm{T}_{\mathrm{p}}}{\partial \tau^{*}} \text {. }
$$

Discretizing equation (55) using the simple explicit and first order finite difference formulation gives:

$$
\begin{aligned}
& \frac{\mathrm{T}_{\mathrm{p} 1, \mathrm{i}+1}^{\mathrm{n}}-\mathrm{T}_{\mathrm{p} 2, \mathrm{i}+2}^{\mathrm{n}}}{\Delta \mathrm{r}}+\frac{\mathrm{T}_{\mathrm{p} 3, \mathrm{i}+3}^{\mathrm{n}}-\mathrm{T}_{\mathrm{p} 2, \mathrm{i}+2}^{\mathrm{n}}}{\Delta \mathrm{r}} \\
& =\frac{\ell_{\mathrm{p}} \mathrm{C}_{\mathrm{pp}}}{\mathrm{k}_{\mathrm{p}}} \frac{\mathrm{T}_{\mathrm{p} 2, \mathrm{i}+2}^{\mathrm{n}+1}-\mathrm{T}_{\mathrm{p} 2, \mathrm{i}+2}^{\mathrm{n}}}{\Delta \mathrm{r}} \Delta \mathrm{r}
\end{aligned}
$$

Multiplying though by $\Delta \mathrm{r}$ gives

$$
\begin{aligned}
\mathrm{T}_{\mathrm{p} 1, \mathrm{i}+1}^{\mathrm{n}}-2 \mathrm{~T}_{\mathrm{p} 2, \mathrm{i}+2}^{\mathrm{n}} & +\mathrm{T}_{\mathrm{p} 3, \mathrm{i}+3}^{\mathrm{n}} \\
= & \frac{\ell_{\mathrm{p}} \mathrm{C}_{\mathrm{pp}} \Delta \mathrm{r}^{2}}{\mathrm{~K}_{\mathrm{p}} \Delta \mathrm{t}}\left(\mathrm{T}_{\mathrm{p} 2, \mathrm{i}+2}^{\mathrm{n}+1}-\mathrm{T}_{\mathrm{p} 2, \mathrm{i}+2}^{\mathrm{n}}\right)
\end{aligned}
$$




$$
\begin{aligned}
\mathrm{T}_{\mathrm{p} 1, \mathrm{i}+1}^{\mathrm{n}}-2 \mathrm{~T}_{\mathrm{p} 2, \mathrm{i}+2}^{\mathrm{n}} & +\mathrm{T}_{\mathrm{p} 3, \mathrm{i}+3}^{\mathrm{n}} \\
= & \frac{\Delta \mathrm{r}^{2}}{\alpha_{\mathrm{p}} \Delta \mathrm{t}}\left(\mathrm{T}_{\mathrm{p} 2, \mathrm{i}+2}^{\mathrm{n}+1}-\mathrm{T}_{\mathrm{p} 2, \mathrm{i}+2}^{\mathrm{n}}\right)
\end{aligned}
$$

Multiplying equation (58) by $\frac{\alpha_{\mathrm{p}} \Delta \mathrm{t}}{\Delta \mathrm{r}^{2}}$ gives

$$
\begin{gathered}
\frac{\alpha_{\mathrm{p}} \Delta \mathrm{t}}{\Delta \mathrm{r}^{2}} \mathrm{~T}_{\mathrm{p} 1, \mathrm{i}+1}^{\mathrm{n}}-\frac{2 \alpha_{\mathrm{p}} \Delta \mathrm{t}}{\Delta \mathrm{r}^{2}} \mathrm{~T}_{\mathrm{p} 2, \mathrm{i}+2}^{\mathrm{n}}+\frac{\alpha_{\mathrm{p}} \Delta \mathrm{t}}{\Delta \mathrm{r}^{2}} \mathrm{~T}_{\mathrm{p} 3, \mathrm{i}+3}^{\mathrm{n}} \\
=\mathrm{T}_{\mathrm{p} 2, \mathrm{i}+2}^{\mathrm{n}+1}-\mathrm{T}_{\mathrm{p} 2, \mathrm{i}+2}^{\mathrm{n}}
\end{gathered}
$$

Where $F_{0}=\frac{\alpha_{p} \Delta t}{\Delta r^{2}}$ is Fourier number so that (59) becomes

$$
\mathrm{F}_{\mathrm{o}}\left(\mathrm{T}_{\mathrm{p} 1, \mathrm{i}+1}^{\mathrm{n}}+\mathrm{T}_{\mathrm{p} 3, \mathrm{i}+3}^{\mathrm{n}}\right)+\left(1-2 \mathrm{~F}_{\mathrm{o}}\right) \mathrm{T}_{\mathrm{p} 2, \mathrm{i}+2}^{\mathrm{n}}=\mathrm{T}_{\mathrm{p} 2, \mathrm{i}+2}^{\mathrm{n}+1}
$$

Rearranging equation (60) gives

$\mathrm{T}_{\mathrm{p} 2, \mathrm{i}+2}^{\mathrm{n}}=\mathrm{F}_{\mathrm{o}}\left(\mathrm{T}_{\mathrm{p} 1, \mathrm{i}+1}^{\mathrm{n}}+\mathrm{T}_{\mathrm{p} 3, \mathrm{i}+3}^{\mathrm{n}}\right)+\left(1-2 \mathrm{~F}_{\mathrm{o}}\right) \mathrm{T}_{\mathrm{p} 2, \mathrm{i}+2}^{\mathrm{n}}(61)$

Equation (61) can be written for Node 1 as seen in equation (62)

$$
\begin{aligned}
& \mathrm{T}_{\mathrm{p} 1, \mathrm{i}+1}^{\mathrm{n}+1}=\mathrm{F}_{\mathrm{o}}\left(\mathrm{T}_{\mathrm{po}, \mathrm{i}}^{\mathrm{n}}+\mathrm{T}_{\mathrm{p} 2, \mathrm{i}+2}^{\mathrm{n}}\right) \\
&+\left(1-2 \mathrm{~F}_{\mathrm{o}}\right) \mathrm{T}_{\mathrm{p} 1, \mathrm{i}+1}^{\mathrm{n}}
\end{aligned}
$$

By substituting parameters in Tables 1, 2 and 3 into equation (62), the numerical value of $\mathrm{F}_{0}$, is obtained, where the computational time interval $\Delta t$ is derived from a stability criterion analysis of the Paraffin wax performed in equation (87).Therefore, equation (62) becomes

$$
\begin{gathered}
\mathrm{T}_{\mathrm{p} 1, \mathrm{i}+1}^{\mathrm{n}+1}=0.499\left(\mathrm{~T}_{\mathrm{po}, \mathrm{i}}^{\mathrm{n}}+\mathrm{T}_{\mathrm{p} 2, \mathrm{i}+2}^{\mathrm{n}}\right)+2 \\
* 10^{-3} \mathrm{~T}_{\mathrm{p} 1, \mathrm{i}+1}^{\mathrm{n}}
\end{gathered}
$$

Equation (63) is the numerical algorithm use to predict the temperature at node 1 and can be written for nodes $2-43$ at new time steps forming a set of $\mathrm{N}$ algebraic linear equations.

Node 1:

$$
\begin{aligned}
& \mathrm{T}_{\mathrm{P} 1, \mathrm{i}}^{\mathrm{n}+1}=0.49\left(\mathrm{~T}_{\mathrm{P} 0, \mathrm{i}}^{\mathrm{n}}+\mathrm{T}_{\mathrm{P} 2, \mathrm{i}+2}^{\mathrm{n}}\right)+2 \times 10^{-3} \mathrm{~T}_{\mathrm{P} 1, \mathrm{i}+1}^{\mathrm{n}} \\
& \mathrm{T}_{\mathrm{P} 1, \mathrm{i}}^{\mathrm{n}+1}=0.49\left(\mathrm{~T}_{\mathrm{P} 0, \mathrm{i}}^{\mathrm{n}}+\mathrm{T}_{\mathrm{P} 2, \mathrm{i}+2}^{\mathrm{n}}\right)+2 \times 10^{-3} \mathrm{~T}_{\mathrm{P} 1, \mathrm{i}+1}^{\mathrm{n}+1} \\
& \mathrm{~T}_{\mathrm{P} 1, \mathrm{i}}^{\mathrm{n}+\infty}=0.49\left(\mathrm{~T}_{\mathrm{P} 0, \mathrm{i}}^{\mathrm{n}+(\infty-1)} \mathrm{T}_{\mathrm{P} 2, \mathrm{i}+2}^{\mathrm{n}+(\infty-1)}\right)+2 \times \\
& 10^{-3} \mathrm{~T}_{\mathrm{P} 1, \mathrm{i}+1}^{\mathrm{n}+(\infty-1)}
\end{aligned}
$$

Node 2 - 43:

$\mathrm{T}_{\mathrm{P} 2, \mathrm{i}+2}^{\mathrm{n}+1}=0.49\left(\mathrm{~T}_{\mathrm{P} 1, \mathrm{i}+1}^{\mathrm{n}}+\mathrm{T}_{\mathrm{P} 3, \mathrm{i}+3}^{\mathrm{n}}\right)+2 \times 10^{-3} \mathrm{~T}_{\mathrm{P} 2, \mathrm{i}+2}^{\mathrm{n}}$

$\mathrm{T}_{\mathrm{P} 3, \mathrm{i}+3}^{\mathrm{n}+1}=0.49\left(\mathrm{~T}_{\mathrm{P} 2, \mathrm{i}+2}^{\mathrm{n}}+\mathrm{T}_{\mathrm{P} 4, \mathrm{i}+4}^{\mathrm{n}}\right)+2 \times 10^{-3} \mathrm{~T}_{\mathrm{P} 3, \mathrm{i}+3}^{\mathrm{n}+1}$

$T_{P 43, i+43}^{n+1}=0.49\left(T_{P 42, i+42}^{n}+T_{P 44, i}^{n}\right)+2 \times$ $10^{-3} T_{P 43, i+43}^{n}$

\subsubsection{Energy balance analysis about internal nodes 1-43 of the PCM (paraffin wax)}

The energy balance analysis of the PCM used accounts for the energy stored and released during the melting and solidification processes. The numerical model solution for the PCM energy balance equation has been presented in the work done by [11]. In this study, the phase change processes are developed for PCM nodes $0, \frac{i}{2}-43, i / 2$ interacting with the HDPE spherical material.

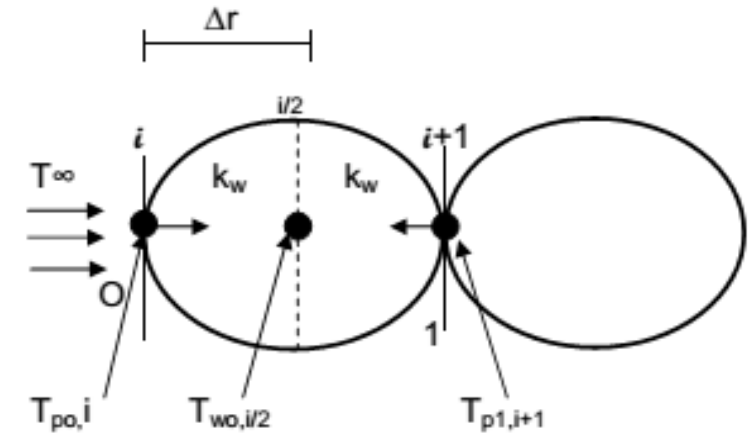

Figure 7: Energy balance analysis of paraffin wax about center nodes 0, i/2 -43,i/2, Source: [11]

The applicable energy equation as presented in [11] can be expressed as:

$$
\begin{aligned}
\ell_{\mathrm{w}} \mathrm{C}_{\mathrm{pw}} \mathrm{A}_{\mathrm{s}} \frac{\partial \mathrm{T}_{\mathrm{w}}}{\partial \mathrm{t}}= & \emptyset+\frac{\mathrm{k}_{\mathrm{w}}}{\mathrm{r}^{2}} \mathrm{~A}_{\mathrm{s}} \frac{\partial}{\partial \mathrm{r}} \frac{\mathrm{r}^{2} \partial\left(\mathrm{T}_{\mathrm{p}_{0}}-\mathrm{T}_{\mathrm{w} 0, \mathrm{i} / 2}\right)}{\partial \mathrm{r}} \\
& +\frac{\mathrm{k}_{\mathrm{w}}}{\mathrm{r}^{2}} \mathrm{~A}_{\mathrm{s}} \frac{\partial}{\partial \mathrm{r}} \frac{\mathrm{r}^{2} \partial\left(\mathrm{T}_{\mathrm{p}_{1}}-\mathrm{T}_{\mathrm{w} 0, \mathrm{i} / 2}\right)}{\partial \mathrm{r}} \\
& +\mathrm{A}_{\mathrm{s}} \partial \mathrm{r}
\end{aligned}
$$

Applying the assumptions simplifies equation (64) and yields;

$$
\begin{aligned}
\ell_{\mathrm{w}} \mathrm{C}_{\mathrm{pw}} \mathrm{A}_{\mathrm{s}} \frac{\partial \mathrm{T}_{\mathrm{w}}}{\partial \mathrm{t}}= & \frac{\mathrm{k}_{\mathrm{w}}}{\mathrm{r}} \mathrm{A}_{\mathrm{s}} \frac{\partial^{2}\left(\mathrm{r}\left(T_{p_{0}}-\mathrm{T}_{\mathrm{w} 0, \mathrm{i} / 2}\right)\right)}{\partial \mathrm{r}^{2}} \\
& +\frac{\mathrm{k}_{\mathrm{w}}}{\mathrm{r}} \mathrm{A}_{\mathrm{s}} \frac{\partial^{2}\left(\mathrm{r}\left(\mathrm{T}_{\mathrm{p}_{1}}-\mathrm{T}_{\mathrm{w} 0, \mathrm{i} / 2}\right)\right)}{\partial \mathrm{r}^{2}} \\
& +\mathrm{A}_{\mathrm{s}} \partial \mathrm{r}
\end{aligned}
$$

Initial Conditions:

Paraffin wax capsule;

$$
\begin{aligned}
& \mathrm{T}_{\mathrm{w}\left(\mathrm{r}_{\mathrm{h}}, 0\right)}=\mathrm{T}_{\mathrm{w}_{\text {initial }}}=\mathrm{T}_{\mathrm{p} \text { initial }} \\
& \mathrm{T}_{\mathrm{w}\left(\mathrm{r}_{0}, 0\right)}=\mathrm{T}_{\mathrm{w}_{\text {inital }}}=\mathrm{T}_{\mathrm{p} \text { intial }} \\
& \mathrm{T}_{\mathrm{w}\left(\frac{\mathrm{r}_{\mathrm{h}}}{2}, 0\right)}=\mathrm{T}_{\mathrm{w}_{\text {inital }}}=\mathrm{T}_{\mathrm{p} \text { initial }}
\end{aligned}
$$

Boundary Conditions:

$$
\begin{aligned}
& \mathrm{T}_{\mathrm{w}\left(\mathrm{r}_{0}, \mathrm{t}\right)}=-\frac{\mathrm{h}_{\mathrm{w}}}{\mathrm{k}_{\mathrm{w}}}\left[\mathrm{T}_{\mathrm{p}(0, \mathrm{t})}-\mathrm{T}_{\mathrm{w}\left(\frac{\mathrm{r}_{0}}{2}, \mathrm{t}\right)}\right] \\
& \mathrm{T}_{\mathrm{w}\left(\mathrm{r}_{\mathrm{h}}, \mathrm{t}\right)}=-\frac{\mathrm{h}_{\mathrm{w}}}{\mathrm{k}_{\mathrm{w}}}\left[\mathrm{T}_{\mathrm{p}(43, \mathrm{t})}-\mathrm{T}_{\left.\mathrm{w}\left(\frac{\mathrm{r}_{\mathrm{h}}}{2}, \mathrm{t}\right)\right]}\right]
\end{aligned}
$$

To simplify the governing equation (65) for a suitable application of numerical approach, the following applicable dimensionless parameters are defined.

$$
\mathrm{r}^{*}=\frac{\mathrm{r}}{\mathrm{r}_{\mathrm{h}}}, \tau^{*}=\frac{\mathrm{t}}{\mathrm{t}_{0}}, \theta=\frac{\mathrm{T}-\mathrm{T}_{\mathrm{w}}}{\mathrm{T}_{\mathrm{p}}-\mathrm{T}_{\mathrm{w}}}
$$

According to [11], substituting $\mathrm{T}_{\mathrm{w}}=\mathrm{T}_{\mathrm{p}_{0}}-\mathrm{T}_{\mathrm{w} 0, \mathrm{i} / 2}$ and $\mathrm{T}_{\mathrm{p}}=\mathrm{T}_{\mathrm{p}_{1}}-\mathrm{T}_{\mathrm{w} 0, \mathrm{i} / 2}$ with the dimensionless parameters into equation (65) gives 


$$
\begin{aligned}
\ell_{\mathrm{w}} \mathrm{C}_{\mathrm{pw}} \mathrm{A}_{\mathrm{s}} \mathrm{t}_{0} \mathrm{r}^{*} \mathrm{r}_{\mathrm{h}} \frac{\partial \mathrm{T}_{\mathrm{w}}}{\partial \tau^{*}} & \\
& =\mathrm{k}_{\mathrm{w}} \mathrm{A}_{\mathrm{s}} \mathrm{t}_{0} \frac{\partial\left(\mathrm{T}-\mathrm{T}_{\mathrm{w}}\right)+\mathrm{T}_{\mathrm{p}}}{\partial \mathrm{r}^{*} \partial \theta} \\
& +\mathrm{k}_{\mathrm{w}} \mathrm{A}_{\mathrm{s}} \mathrm{t}_{0} \mathrm{r}^{*} \mathrm{r}_{\mathrm{h}} \frac{\partial\left(\mathrm{T}-\mathrm{T}_{\mathrm{w}}\right)+\mathrm{T}_{\mathrm{w}}}{\partial \mathrm{r}^{*} \partial \theta} \\
& +\mathrm{A}_{\mathrm{s}} \mathrm{t}_{0} \mathrm{r}^{*} \mathrm{r}_{\mathrm{h}} \partial \mathrm{r}
\end{aligned}
$$

Dividing through by $A_{s} t_{0} r^{*} r_{h}$ gives

$$
\begin{aligned}
\ell_{\mathrm{w}} \mathrm{C}_{\mathrm{pw}} \frac{\partial \mathrm{T}_{\mathrm{w}}}{\partial \tau^{*}}=\frac{\mathrm{k}_{\mathrm{w}}}{\mathrm{r}^{*} \mathrm{r}_{\mathrm{h}}} & \frac{\partial\left(\mathrm{T}-\mathrm{T}_{\mathrm{w}}\right)+\mathrm{T}_{\mathrm{p}}}{\partial \mathrm{r}^{*} \partial \theta} \\
& +\frac{\mathrm{k}_{\mathrm{w}}}{\mathrm{r}^{*} \mathrm{r}_{\mathrm{h}}} \frac{\partial\left(\mathrm{T}-\mathrm{T}_{\mathrm{w}}\right)+\mathrm{T}_{\mathrm{w}}}{\partial \theta}+\frac{\partial \mathrm{r}}{\mathrm{r}^{*} \mathrm{r}_{\mathrm{h}}}
\end{aligned}
$$

Dividing equation (73) through by $\mathrm{k}_{\mathrm{w}}$ and multiplying the solution by $\propto_{\mathrm{w}}=\frac{\mathrm{k}_{\mathrm{w}}}{\ell_{\mathrm{w}} \mathrm{C}_{\mathrm{pw}}}$ gives:

$$
\begin{gathered}
\frac{\partial \mathrm{T}_{\mathrm{w}}}{\partial \tau^{*}}=\frac{\propto_{\mathrm{w}}}{\mathrm{r}^{*} \mathrm{r}_{\mathrm{h}}} \frac{\partial\left(\mathrm{T}-\mathrm{T}_{\mathrm{w}}\right)+\mathrm{T}_{\mathrm{p}}}{\partial \mathrm{r}^{*} \partial \theta}+\frac{\propto_{\mathrm{w}}}{\mathrm{r}^{*} \mathrm{r}_{\mathrm{h}}} \frac{\partial\left(\mathrm{T}-\mathrm{T}_{\mathrm{w}}\right)+\mathrm{T}_{\mathrm{w}}}{\partial \mathrm{r}^{*} \partial \theta} \\
+\propto_{\mathrm{w}} \frac{\partial \mathrm{r}}{\mathrm{r}^{*} \mathrm{r}_{\mathrm{h}}}
\end{gathered}
$$

By order of magnitude analysis of equation (74), both terms in the RHS are compared to have about the same magnitude, hence we have no justification to neglect one in preference to the other, hence both terms are retained [11].

Substituting $\mathrm{T}_{\mathrm{w}}=\mathrm{T}_{\mathrm{p}_{0}}-\mathrm{T}_{\mathrm{w} 0, \mathrm{i} / 2}, \mathrm{~T}_{\mathrm{p}}=\mathrm{T}_{\mathrm{p}_{1}}-\mathrm{T}_{\mathrm{w} 0, \mathrm{i} / 2}$ and $\theta=\frac{\mathrm{T}-\mathrm{T}_{\mathrm{w}}}{\mathrm{T}_{\mathrm{p}}-\mathrm{T}_{\mathrm{w}}}$ back to equation (74) yields

$$
\begin{gathered}
\frac{\partial \mathrm{T}_{\mathrm{w}}}{\partial \tau^{*}}=\frac{\propto_{\mathrm{w}}}{\mathrm{r}^{*} \mathrm{r}_{\mathrm{h}}} \frac{\partial\left(\mathrm{T}_{\mathrm{p}_{0}}-\mathrm{T}_{\mathrm{w} 0, \mathrm{i} / 2}\right)}{\partial \mathrm{r}^{*}}+\frac{\propto_{\mathrm{w}}}{\mathrm{r}^{*} \mathrm{r}_{\mathrm{h}}} \frac{\partial\left(\mathrm{T}_{\mathrm{p}_{1}}-\mathrm{T}_{\mathrm{w} 0, \mathrm{i} / 2}\right)}{\partial \mathrm{r}^{*}} \\
+\propto_{\mathrm{w}} \frac{\partial \mathrm{r}}{\mathrm{r}^{*} \mathrm{r}_{\mathrm{h}}}
\end{gathered}
$$

Multiplying through by $\frac{\mathrm{r}^{*} r_{h}}{\alpha_{w}}$ gives

$$
\begin{gathered}
\frac{\mathrm{r}^{*} \mathrm{r}_{\mathrm{h}}}{\alpha_{\mathrm{w}}} \frac{\partial \mathrm{T}_{\mathrm{w}}}{\partial \tau^{*}}=\frac{\partial\left(\mathrm{T}_{\mathrm{p}_{0}}-\mathrm{T}_{\mathrm{w} 0, \mathrm{i} / 2}\right)}{\partial \mathrm{r}^{*}}+\frac{\partial\left(\mathrm{T}_{\mathrm{p}_{1}}-\mathrm{T}_{\mathrm{w} 0, \mathrm{i} / 2}\right)}{\partial \mathrm{r}^{*}} \\
+\partial \mathrm{r}
\end{gathered}
$$

Equation (76) is multiplied by $\propto_{\mathrm{w}}=\frac{\mathrm{k}_{\mathrm{w}}}{\ell_{\mathrm{w}} \mathrm{C}_{\mathrm{pw}}}$, where $\mathrm{r}^{*}=$ $\frac{\mathrm{r}}{\mathrm{r}_{\mathrm{h}}}$ to yield

$$
\begin{aligned}
\frac{\mathrm{r} \partial \mathrm{T}_{\mathrm{w}}}{\partial \tau^{*}}=\frac{\mathrm{k}_{\mathrm{w}}}{\ell_{\mathrm{w}} \mathrm{C}_{\mathrm{pw}}} & \frac{\partial\left(\mathrm{T}_{\mathrm{p}_{0}}-\mathrm{T}_{\mathrm{w} 0, \mathrm{i} / 2)}\right.}{\partial \mathrm{r}^{*}} \\
& +\frac{\mathrm{k}_{\mathrm{w}}}{\ell_{\mathrm{w}} \mathrm{C}_{\mathrm{pw}}} \frac{\partial\left(\mathrm{T}_{\mathrm{p}_{1}}-\mathrm{T}_{\mathrm{w} 0, \mathrm{i} / 2}\right)}{\partial \mathrm{r}^{*}} \\
& +\frac{\mathrm{k}_{\mathrm{w}}}{\ell_{\mathrm{w}} \mathrm{C}_{\mathrm{pw}}} \partial \mathrm{r}
\end{aligned}
$$

Rearranging equation (77) gives

$$
\begin{gathered}
\frac{\mathrm{k}_{\mathrm{w}}}{\ell_{\mathrm{w}} \mathrm{C}_{\mathrm{pw}}} \frac{\partial\left(\mathrm{T}_{\mathrm{p}_{0}}-\mathrm{T}_{\mathrm{w} 0, \mathrm{i} / 2}\right)}{\partial \mathrm{r}^{*}}+\frac{\mathrm{k}_{\mathrm{w}}}{\ell_{\mathrm{w}} \mathrm{C}_{\mathrm{pw}}} \frac{\partial\left(\mathrm{T}_{\mathrm{p}_{1}}-\mathrm{T}_{\mathrm{w} 0, \mathrm{i} / 2}\right)}{\partial \mathrm{r}^{*}} \\
=\frac{\mathrm{r} \partial \mathrm{T}_{\mathrm{w}}}{\partial \tau^{*}}-\frac{\mathrm{k}_{\mathrm{w}}}{\ell_{\mathrm{w}} \mathrm{C}_{\mathrm{pw}}} \partial \mathrm{r}
\end{gathered}
$$

Multiplying equation (79) by $\partial \mathrm{r}^{*}$ gives

$$
\begin{gathered}
\frac{\mathrm{k}_{\mathrm{w}}}{\ell_{\mathrm{w}} \mathrm{C}_{\mathrm{pw}}}\left(\mathrm{T}_{\mathrm{p}_{0}}-\mathrm{T}_{\mathrm{w} 0, \mathrm{i} / 2}\right)+\frac{\mathrm{k}_{\mathrm{w}}}{\ell_{\mathrm{w}} \mathrm{C}_{\mathrm{pw}}}\left(\mathrm{T}_{\mathrm{p}_{1}}-\mathrm{T}_{\mathrm{w} 0, \mathrm{i} / 2}\right) \\
=\frac{\partial^{2} \mathrm{~T}_{\mathrm{w}} \mathrm{r} \cdot \mathrm{r}^{*}}{\partial \tau^{*}}-\frac{\mathrm{k}_{\mathrm{w}} \partial \mathrm{r} \partial \mathrm{r}^{*}}{\ell_{\mathrm{w}} \mathrm{C}_{\mathrm{pw}}}
\end{gathered}
$$

Discretizing equation (79) using the simple explicit and first-order finite difference formulation gives:

$$
\begin{array}{r}
\frac{\mathrm{k}_{\mathrm{w}}}{\ell_{\mathrm{w}} \mathrm{C}_{\mathrm{pw}}}\left(\mathrm{T}_{\mathrm{po}, \mathrm{i}}^{\mathrm{n}}-\mathrm{T}_{\mathrm{wo}, \mathrm{i} / 2}^{\mathrm{n}}\right)+\frac{\mathrm{k}_{\mathrm{w}}}{\ell_{\mathrm{w}} \mathrm{C}_{\mathrm{pw}}}\left(\mathrm{T}_{\mathrm{p} 1, \mathrm{i}+1}^{\mathrm{n}}-\mathrm{T}_{\mathrm{wo}, \mathrm{i} / 2}^{\mathrm{n}}\right) \\
=\frac{\mathrm{T}_{\mathrm{wo}, \mathrm{i} / 2}^{\mathrm{n}+1}-\mathrm{T}_{\mathrm{wo}, \mathrm{i} / 2}^{\mathrm{n}}}{\Delta \mathrm{t}} \Delta \mathrm{r}^{2}-\frac{k_{w} \Delta \mathrm{r}^{2}}{\ell_{\mathrm{w}} \mathrm{C}_{\mathrm{pw}}}
\end{array}
$$

Collecting like terms and multiplying through by $\frac{\ell_{\mathrm{w}} \mathrm{C}_{\mathrm{pw}}}{k_{w}}$ gives

$$
\begin{aligned}
\mathrm{T}_{\mathrm{po}, \mathrm{i}}^{\mathrm{n}}-2 \mathrm{~T}_{\mathrm{wo}, \frac{\mathrm{i}}{2}}^{\mathrm{n}}+ & \mathrm{T}_{\mathrm{p} 1, \mathrm{i}+1}^{\mathrm{n}} \\
& =\frac{\ell_{\mathrm{w}} \mathrm{C}_{\mathrm{pw}} \Delta \mathrm{r}^{2}}{\mathrm{k}_{\mathrm{w}} \Delta \mathrm{t}}\left(\mathrm{T}_{\text {wo }, \frac{\mathrm{i}}{2}}^{\mathrm{n}+1}-\mathrm{T}_{\text {wo }, \frac{\mathrm{i}}{2}}^{\mathrm{n}}\right) \\
& -\Delta \mathrm{r}^{2}
\end{aligned}
$$

Further rearranging gives

$$
\begin{aligned}
\mathrm{T}_{\mathrm{po}, \mathrm{i}}^{\mathrm{n}}-2 \mathrm{~T}_{\mathrm{wo}, \frac{\mathrm{i}}{2}}^{\mathrm{n}}+ & \mathrm{T}_{\mathrm{p} 1, \mathrm{i}+1}^{\mathrm{n}}+\Delta \mathrm{r}^{2} \\
& =\frac{\ell_{\mathrm{w}} \mathrm{C}_{\mathrm{pw}} \Delta \mathrm{r}^{2}}{\mathrm{k}_{\mathrm{w}} \Delta \mathrm{t}}\left(\mathrm{T}_{\mathrm{wo}, \frac{\mathrm{i}}{2}}^{\mathrm{n}+1}-\mathrm{T}_{\text {wo }, \frac{\mathrm{i}}{2}}^{\mathrm{n}}\right)
\end{aligned}
$$

Hence, equation (82) becomes

$$
\begin{aligned}
\mathrm{T}_{\mathrm{po}, \mathrm{i}}^{\mathrm{n}}-2 \mathrm{~T}_{\mathrm{wo}, \frac{\mathrm{i}}{2}}^{\mathrm{n}}+ & \mathrm{T}_{\mathrm{p} 1, \mathrm{i}+1}^{\mathrm{n}}+\Delta \mathrm{r}^{2} \\
& =\frac{\Delta \mathrm{r}^{2}}{\alpha_{\mathrm{w}} \Delta \mathrm{t}}\left(\mathrm{T}_{\text {wo, } \frac{\mathrm{i}}{2}}^{\mathrm{n}+1}-\mathrm{T}_{\text {wo }, \frac{\mathrm{i}}{2}}^{\mathrm{n}}\right)
\end{aligned}
$$

Multiplying equation (83) by $\frac{\alpha_{\mathrm{w}} \Delta \mathrm{t}}{\Delta \mathrm{r}^{2}}$ gives

$$
\begin{gathered}
\frac{\alpha_{\mathrm{w}} \Delta \mathrm{t}}{\Delta \mathrm{r}^{2}} \mathrm{~T}_{\mathrm{po}, \mathrm{i}}^{\mathrm{n}}-\frac{2 \alpha_{\mathrm{w}} \Delta \mathrm{t}}{\Delta \mathrm{r}^{2}} \mathrm{~T}_{\mathrm{wo}, \frac{\mathrm{i}}{2}}^{\mathrm{n}}+\frac{\alpha_{\mathrm{w}} \Delta \mathrm{t}}{\Delta \mathrm{r}^{2}} \mathrm{~T}_{\mathrm{p} 1, \mathrm{i}+1}^{\mathrm{n}}+\alpha_{\mathrm{w}} \Delta \mathrm{t} \\
=\mathrm{T}_{\text {wo }, \frac{\mathrm{i}}{2}}^{\mathrm{n}+1}-\mathrm{T}_{\text {wo }, \frac{\mathrm{i}}{2}}^{\mathrm{n}}
\end{gathered}
$$

Rearranging equation (84) gives

$$
\begin{aligned}
\mathrm{T}_{\mathrm{wo}, \mathrm{i} / 2}^{\mathrm{n}+1}-\mathrm{T}_{\mathrm{wo}, \frac{\mathrm{i}}{2}}^{\mathrm{n}}= & \frac{\alpha_{\mathrm{w}} \Delta \mathrm{t}}{\Delta \mathrm{r}^{2}} \mathrm{~T}_{\mathrm{po}, \mathrm{i}}^{\mathrm{n}}-\frac{2 \alpha_{\mathrm{w}} \Delta \mathrm{t}}{\Delta \mathrm{r}^{2}} \mathrm{~T}_{\text {wo }, \frac{\mathrm{i}}{2}}^{\mathrm{n}} \\
& +\frac{\alpha_{\mathrm{w}} \Delta \mathrm{t}}{\Delta \mathrm{r}^{2}} \mathrm{~T}_{\mathrm{p} 1, \mathrm{i}+1}^{\mathrm{n}}+\alpha_{\mathrm{w}} \Delta \mathrm{t}
\end{aligned}
$$

Where $F_{o}=\frac{\alpha_{w} \Delta t}{\Delta r^{2}}$ is the Fourier number so that equation (85) becomes:

$$
\begin{aligned}
\mathrm{F}_{\mathrm{o}}\left(\mathrm{T}_{\mathrm{po}, \mathrm{i}}^{\mathrm{n}}+\mathrm{T}_{\mathrm{p} 1, \mathrm{i}+1}^{\mathrm{n}}\right. & \left.+\alpha_{\mathrm{w}} \Delta \mathrm{t}\right)+\left(1-2 \mathrm{~F}_{\mathrm{o}}\right) \mathrm{T}_{\mathrm{wo}, \mathrm{i} / 2}^{\mathrm{n}} \\
= & \mathrm{T}_{\mathrm{wo}, \mathrm{i} / 2}^{\mathrm{n}+1}
\end{aligned}
$$

Rearranging equation (86) gives

$$
\begin{array}{r}
\mathrm{T}_{\mathrm{wo}, \mathrm{i} / 2}^{\mathrm{n}+1}=\mathrm{F}_{\mathrm{o}}\left(\mathrm{T}_{\mathrm{po}, \mathrm{i}}^{\mathrm{n}}+\mathrm{T}_{\mathrm{p}, \mathrm{i}+1}^{\mathrm{n}}+\alpha_{\mathrm{w}} \Delta \mathrm{t}\right) \\
+\left(1-2 \mathrm{~F}_{\mathrm{o}}\right) \mathrm{T}_{\mathrm{wo}, \mathrm{i} / 2}^{\mathrm{n}}
\end{array}
$$

Applying the stability criterion to equation (87), requires that the coefficient $\mathrm{T}_{\mathrm{wo}, \mathrm{i} / 2}^{\mathrm{n}}$ be greater than or equal to zero so that $\Delta t-$ simulation time interval is selected to be well within the stability limit which corresponds to the value of $F_{0}[11]$. 


$$
\begin{gathered}
\left(1-2 \mathrm{~F}_{\mathrm{o}}\right) \mathrm{F}_{\mathrm{o}} \geq 0 ; \mathrm{F}_{\mathrm{o}} \leq \frac{1}{2} ; \Delta \mathrm{t}=\frac{\mathrm{F}_{\mathrm{o}} \Delta \mathrm{r}^{2}}{\alpha_{\mathrm{w}}} ; \mathrm{F}_{\mathrm{o}}=\frac{\alpha_{\mathrm{w}} \Delta \mathrm{t}}{\Delta \mathrm{r}^{2}} \\
=0.49
\end{gathered}
$$

Substituting parameters for $\Delta \mathrm{r}^{2}, \mathrm{~F}_{\mathrm{o}}$ and $\alpha_{\mathrm{w}}$ for convergence and stability of the numerical results, the minimum permissible value for the computation time interval is $\Delta \mathrm{t} \approx 1 \mathrm{hr}$. By substituting $\mathrm{F}_{\mathrm{o}}$ into equation (87) gives

$$
\begin{gathered}
\mathrm{T}_{\mathrm{w}, \mathrm{i} / 2}^{\mathrm{n}+1}=0.49\left(\mathrm{~T}_{\mathrm{po}, \mathrm{i}}^{\mathrm{n}}+\mathrm{T}_{\mathrm{p} 1, \mathrm{i}+1}^{\mathrm{n}}+\frac{\mathrm{k}_{\mathrm{w}}}{\ell_{\mathrm{w}} \mathrm{C}_{\mathrm{pw}}} \Delta \mathrm{t}\right) \\
+0.02 \mathrm{~T}_{\mathrm{wo}, \mathrm{i} / 2}^{\mathrm{n}}
\end{gathered}
$$

Equation (88) is the numerical model used to predict the phase change phenomenon of paraffin wax at nodes $0, \mathrm{i} / 2-43, \mathrm{i} / 2$ which interacts with the HDPE capsule wall. The model can be written at new time steps forming a set of $\mathrm{N}$-algebraic linear equations solvable using MATLAB [11].

Node $0, \frac{i}{2}$ :

$$
\mathrm{T}_{\mathrm{wo}, \mathrm{i} / 2}^{\mathrm{n}+1}=0.49\left(\mathrm{~T}_{\mathrm{Po}, \mathrm{i}}^{\mathrm{n}}+\mathrm{T}_{\mathrm{P} 1, \mathrm{i}+1}^{\mathrm{n}}+\frac{\mathrm{k}_{\mathrm{w}}}{\ell_{\mathrm{w}} \mathrm{C}_{\mathrm{pw}}} \Delta \mathrm{t}\right)+
$$

$0.02 \mathrm{~T}_{\mathrm{wo}, \mathrm{i} / 2}^{\mathrm{n}}$

$\mathrm{T}_{\mathrm{wo}, \mathrm{i} / 2}^{\mathrm{n}+2}=0.49\left(\mathrm{~T}_{\mathrm{Po}, \mathrm{i}}^{\mathrm{n}+1}+\mathrm{T}_{\mathrm{Po}, \mathrm{i}}^{\mathrm{n}+1}+\frac{\mathrm{k}_{\mathrm{w}}}{\ell_{\mathrm{w}} \mathrm{C}_{\mathrm{pw}}} \Delta \mathrm{t}\right)+$

$0.02 \mathrm{~T}_{\mathrm{wo}, \mathrm{i} / 2}^{\mathrm{n}}$

$\mathrm{T}_{\mathrm{wo}, \mathrm{i} / 2}^{\mathrm{n}+\infty}=0.49\left(\mathrm{~T}_{\mathrm{Po}, \mathrm{i}}^{\mathrm{n}+(\infty-1)}+\mathrm{T}_{\mathrm{Po}, \mathrm{i}}^{\mathrm{n}+(\infty-1)}+\frac{\mathrm{k}_{\mathrm{w}}}{\ell_{\mathrm{w}} \mathrm{C}_{\mathrm{pw}}} \Delta \mathrm{t}\right)+$

$0.02 \mathrm{~T}_{\mathrm{wo}, \mathrm{i} / 2}^{\mathrm{n}+(\infty-1)}$

Node $0, \frac{\mathrm{i}}{2}-43, \frac{\mathrm{i}}{2}$ :

$$
\mathrm{T}_{\mathrm{wo}, \mathrm{i} / 2}^{\mathrm{n}+1}=0.49\left(\mathrm{~T}_{\mathrm{P} 1, \mathrm{i}+1}^{\mathrm{n}}+\mathrm{T}_{\mathrm{P} 2, \mathrm{i}+2}^{\mathrm{n}}+\frac{\mathrm{k}_{\mathrm{w}}}{\ell_{\mathrm{w}} \mathrm{C}_{\mathrm{pw}}} \Delta \mathrm{t}\right)+
$$

$0.02 \mathrm{~T}_{\mathrm{w} 1, \mathrm{i} / 2}^{\mathrm{n}}$

$\mathrm{T}_{\mathrm{w} 2, \mathrm{i} / 2}^{\mathrm{n}+1}=0.49\left(\mathrm{~T}_{\mathrm{P} 2, \mathrm{i}+2}^{\mathrm{n}}+\mathrm{T}_{\mathrm{P} 3, \mathrm{i}+3}^{\mathrm{n}}+\frac{\mathrm{k}_{\mathrm{w}}}{\ell_{\mathrm{w}} \mathrm{C}_{\mathrm{pw}}} \Delta \mathrm{t}\right)+$

$0.02 \mathrm{~T}_{\mathrm{w} 2, \mathrm{i} / 2}^{\mathrm{n}}$

$\mathrm{T}_{\mathrm{w} 43, \mathrm{i} / 2}^{\mathrm{n}+1}=0.49\left(\mathrm{~T}_{\mathrm{P} 43, \mathrm{i}+43}^{\mathrm{n}}+\mathrm{T}_{\mathrm{P} 44, \mathrm{i}}^{\mathrm{n}}+\frac{\mathrm{k}_{\mathrm{w}}}{\ell_{\mathrm{w}} \mathrm{C}_{\mathrm{pw}}} \Delta \mathrm{t}\right)+$

$0.02 \mathrm{~T}_{\mathrm{w} 43, \mathrm{i} / 2}^{\mathrm{n}}$

$\mathrm{C}_{\mathrm{pw}}$ is the specific heat capacity of the paraffin wax with melting and solidification boundary conditions stated as follows;

$$
\begin{aligned}
& \mathrm{C}_{\mathrm{pw} \text { (solid) }}=\frac{2 \mathrm{~kJ}}{\mathrm{~kg}} \mathrm{~K} ; \mathrm{T}_{\mathrm{wo}, \mathrm{i} / 2}^{\mathrm{n}}<21^{\circ} \mathrm{C} \\
& \mathrm{C}_{\mathrm{pw} \text { (solid-liquid) }}=\frac{18 \mathrm{~kJ}}{\mathrm{~kg}} \mathrm{~K} ; 23^{\circ} \mathrm{C} \leq \mathrm{T}_{\mathrm{wo}, \mathrm{i} / 2}^{\mathrm{n}} \leq 25^{\circ} \mathrm{C} \\
& \mathrm{C}_{\mathrm{pw} \text { (liquid) }}=3.2 \frac{\mathrm{KJ}}{\mathrm{kg}} \mathrm{K} ; \mathrm{T}_{\mathrm{wo}, \mathrm{i} / 2}^{\mathrm{n} / 2}>25^{\circ} \mathrm{C}
\end{aligned}
$$

\section{RESULTS AND DISCUSSION}

The thermal performance of the developed numerical models for the paraffin wax and HDPE materials is dependent mainly on the Fourier number, $\mathrm{F}_{\mathrm{o}}$ which characterizes transient heat conduction to the rate of thermal energy storage. Table 3 shows the temperature profiles of the PCM (Paraffin wax), HDPEPCM panel air inlet and exit temperatures for simulation day 1-4. From the results, temperature depression in the outdoor air records $7.1^{\circ} \mathrm{C}, 9.2^{\circ} \mathrm{C}, 10.2^{\circ} \mathrm{C}$ and $5.6^{\circ} \mathrm{C}$ for day $1,2,3$ and 4 respectively. The generated data in table 3 indicates that a high average outdoor temperature results to a high temperature drop experienced in HDPE-PCM panel system. Hence, it is expected that with effective reverse suction DC fan(s) placed at strategic points on the conex steel walls, the HDPE-PCM panel medium can effectively cool the indoor space of the conex envelope. Figure 6 - 9 are graphical representations of data in table 3 and noticeable similarity exist between the HDPE material temperature at exist nodes and the HDPE-PCM panel outlet air temperature. The HDPEPCM panel outlet air temperature is observed to maintain values that do not decrease beyond the HDPE material and paraffin wax temperatures which entirely validates the first law of thermodynamics of thermal systems. Figure 10 presents the variations in the PCM temperature due to the varying surrounding ambient temperature passing through the conduit of the HDPE-PCM panel unit. Figure 10 and 11 show the PCM experiencing solid-solid/melting phase changes from 12am - 1am. This melting period accounts for latent heat storage operation between $23-24^{\circ} \mathrm{C}$. It is recommended that a CFD software is used for this simulation to accurately capture visibly the physical and thermal features of the solid - liquid boundary phase change domain in a post process simulation procedure. In Figure 10, the temperature drop in the paraffin wax and HDPE material at exit nodes is consistent from $1 \mathrm{am}-11 \mathrm{pm}$ irrespective of the fluctuating outdoor air temperature. This is because of the discharge/solidification phase of the PCM for which the discharged heat is shielded from the air flow during the period. The effect of the convective heat transfer $h_{f}$ of the simulated air from the high pressure axial flow fan, is consequent on the air flowing throughout the HDPE-PCM panel system. This further causes a drop in the air temperature, leaving the conduit of the HDPE-PCM panel unit into the indoor space of the conex envelope. 
Numerical Study of High Density Polyethylene -PCM Capsules for Passive Cooling Application in..., A. N. Udosen

Table 3: PCM (Paraffin wax), HDPE-PCM panel air inlet and exit temperatures for Day 1-4

\begin{tabular}{|c|c|c|c|c|c|c|c|c|c|c|c|c|}
\hline Time & $\begin{array}{c}T_{w},{ }^{\circ} \mathrm{C} \\
\text { for } \\
\text { Day } 1 \\
\text { PCM } \\
\text { in exit } \\
\text { capsul } \\
\text { es }\end{array}$ & $\begin{array}{c}\mathrm{T}_{\mathrm{f},{ }^{\circ} \mathrm{C}} \\
\text { for } \\
\text { Day } 1 \\
\text { (Panel } \\
\text { Inlet } \\
\text { Air) }\end{array}$ & $\begin{array}{c}T_{\mathrm{f},}{ }^{\circ} \mathrm{C} \\
\text { for } \\
\text { Day } 1 \\
\text { (Panel } \\
\text { outlet } \\
\text { Air) }\end{array}$ & $\begin{array}{c}T_{w},{ }^{\circ} \mathrm{C} \\
\text { for } \\
\text { Day } 2 \\
\text { PCM } \\
\text { in exit } \\
\text { capsul } \\
\text { es }\end{array}$ & $\begin{array}{l}T_{\mathrm{f}},{ }^{\circ} \mathrm{C} \\
\text { for } \\
\text { Day } \\
\text { 2(Pan } \\
\text { el Inlet } \\
\text { Air) }\end{array}$ & $\begin{array}{c}T_{\mathrm{f}},{ }^{\circ} \mathrm{C} \\
\text { for } \\
\text { Day } 2 \\
\text { (Panel } \\
\text { outlet } \\
\text { Air) }\end{array}$ & $\begin{array}{c}T_{w},{ }^{\circ} \mathrm{C} \\
\text { for } \\
\text { Day } 3 \\
\text { PCM } \\
\text { in exit } \\
\text { capsul } \\
\text { es }\end{array}$ & $\begin{array}{c}T_{\mathrm{f}},{ }^{\circ} \mathrm{C} \\
\text { for } \\
\text { Day } \\
\text { 3(Pan } \\
\text { el Inlet } \\
\text { Air) }\end{array}$ & $\begin{array}{c}T_{\mathrm{f},}{ }^{\circ} \mathrm{C} \\
\text { for } \\
\text { Day } 3 \\
\text { (Panel } \\
\text { outlet } \\
\text { Air) }\end{array}$ & $\begin{array}{l}T_{\mathrm{w},}{ }^{\circ} \mathrm{C} \\
\text { for } \\
\text { Day } 4 \\
\text { PCM } \\
\text { in exit } \\
\text { capsul } \\
\text { es }\end{array}$ & $\begin{array}{c}\mathrm{T}_{\mathrm{f},{ }^{\circ} \mathrm{C}} \\
\text { for } \\
\text { Day } \\
4(\text { Pan } \\
\text { el Inlet } \\
\text { Air) }\end{array}$ & $\begin{array}{c}\mathrm{T}_{\mathrm{f},{ }^{\circ}}{ }^{\circ} \\
\text { for } \\
\text { Day } 4 \\
\text { (Panel } \\
\text { outlet } \\
\text { Air) }\end{array}$ \\
\hline 12am & 20.0 & 25.5 & 25.4 & 20.0 & 24.5 & 24.4 & 20.0 & 23.8 & 23.7 & 20.0 & $25.5^{*}$ & 25.4 \\
\hline $1 \mathrm{am}$ & 25.3 & 25.2 & 25.4 & 24.3 & 24.5 & 24.4 & 23.7 & 23.6 & 23.7 & 25.3 & 25.2 & 25.4 \\
\hline $2 a m$ & 25.2 & 25.0 & 25.0 & 24.2 & 24.4 & 24.0 & 23.5 & 23.6 & 23.3 & 25.0 & 25.0 & 25.0 \\
\hline $3 a m$ & 24.9 & 25.0 & 24.8 & 23.9 & 24.4 & 23.8 & 23.2 & 23.8 & 23.1 & 24.7 & 25.0 & 24.8 \\
\hline $4 a m$ & 24.5 & 25.0 & 24.3 & 23.6 & 23.7 & 23.4 & 22.9 & 23.5 & 22.7 & 24.3 & 24.7 & 24.3 \\
\hline $5 a m$ & 24.2 & 25.2 & 24.0 & 23.2 & 23.2 & 23.1 & 22.6 & 23.5 & 22.4 & 23.9 & 24.7 & 24.0 \\
\hline $6 a m$ & 23.8 & 25.5 & 23.6 & 22.9 & 24.5 & 22.7 & 22.2 & 23.2 & 22.0 & 23.5 & 25.1 & 23.6 \\
\hline $7 \mathrm{am}$ & 23.5 & 26.5 & 23.3 & 22.6 & 25.5 & 22.4 & 21.9 & 24.2 & 21.8 & 23.2 & 22.1 & 23.3 \\
\hline $8 a m$ & 23.1 & 28.5 & 22.9 & 22.2 & 26.9 & 22.0 & 21.6 & 26.5 & 21.4 & 22.8 & 22.0 & 22.9 \\
\hline $9 a m$ & 22.4 & 28.5 & 22.6 & 21.9 & 27.0 & 21.7 & 21.2 & 28.6 & 21.1 & 22.5 & 22.3 & 22.6 \\
\hline 10am & 22.1 & 29.9 & 22.2 & 21.5 & 27.8 & 21.3 & 20.9 & 29.0 & 20.7 & 22.1 & 22.4 & 22.2 \\
\hline $11 \mathrm{am}$ & 21.7 & 30.0 & 21.9 & 21.2 & 29.0 & 21.0 & 20.6 & 29.9 & 20.4 & 21.7 & 23.4 & 22.9 \\
\hline 12noon & 21.4 & $31.0^{*}$ & 21.5 & 20.9 & 29.5 & 20.7 & 20.3 & 31.0 & 20.1 & 21.4 & 25.0 & 22.2 \\
\hline $1 \mathrm{pm}$ & 21.0 & 30.0 & 21.2 & 20.5 & 30.2 & 20.4 & 19.9 & 31.2 & 19.8 & 21.1 & $25.5^{*}$ & 21.9 \\
\hline $2 \mathrm{pm}$ & 20.7 & 28.6 & 20.8 & 20.2 & $31.0^{*}$ & 20.0 & 19.6 & 31.0 & 19.4 & 20.7 & 25.2 & 21.2 \\
\hline $3 \mathrm{pm}$ & 20.4 & 24.0 & 20.5 & 19.9 & 30.2 & 19.7 & 19.3 & $31.5^{\star}$ & 19.2 & 20.4 & 25.2 & 20.5 \\
\hline $4 \mathrm{pm}$ & 20.0 & 25.0 & 20.2 & 19.6 & 29.0 & 19.4 & 19.0 & 30.6 & 18.8 & 20.1 & 25.5 & 20.2 \\
\hline $5 \mathrm{pm}$ & 19.7 & 25.6 & 19.9 & 19.2 & 28.0 & 19.1 & 18.7 & 28.0 & 18.5 & 19.7 & 25.0 & 19.9 \\
\hline $6 \mathrm{pm}$ & 19.4 & 25.5 & 19.5 & 18.9 & 27.5 & 18.8 & 18.4 & 27.5 & 18.2 & 19.4 & 24.0 & 19.5 \\
\hline $7 \mathrm{pm}$ & 19.1 & 25.1 & 19.2 & 18.6 & 27.0 & 18.5 & 18.1 & 27.4 & 17.9 & 19.1 & 24.0 & 19.2 \\
\hline $8 \mathrm{pm}$ & 18.7 & 25.1 & 18.9 & 18.3 & 26.8 & 18.1 & 17.8 & 27.2 & 17.6 & 18.8 & 23.8 & 18.9 \\
\hline $9 \mathrm{pm}$ & 18.4 & 25.1 & 18.6 & 18.0 & 26.5 & 17.9 & 17.5 & 27.2 & 17.4 & 18.5 & 23.6 & 18.6 \\
\hline 10pm & 18.1 & 25.1 & 18.3 & 17.7 & 26.5 & 17.6 & 17.2 & 27.0 & 17.1 & 18.2 & 23.6 & 18.3 \\
\hline $11 \mathrm{pm}$ & 17.8 & 25.1 & 18.0 & 17.4 & 26.5 & 17.3 & 16.9 & 27.0 & 16.8 & 17.9 & 23.6 & 18.0 \\
\hline $\begin{array}{c}\text { Avg. daily } \\
\text { peak }\end{array}$ & & 31.0 & & & 31.0 & & & 31.5 & & & 25.5 & \\
\hline Temp ${ }^{\circ} \mathrm{C}$ & & & & & & & & & & & & \\
\hline $\begin{array}{c}\text { Avg } \\
\operatorname{Temp~}^{\circ} \mathrm{C}\end{array}$ & & 26.4 & & & 37.9 & & & 26.0 & & & 23.1 & \\
\hline
\end{tabular}




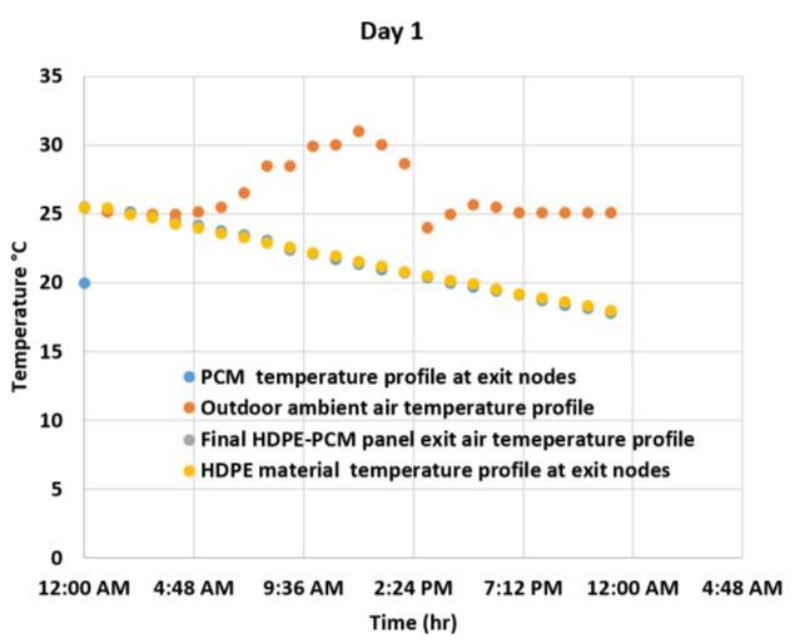

Figure 6: Graph of temperature against time for simulation day 1

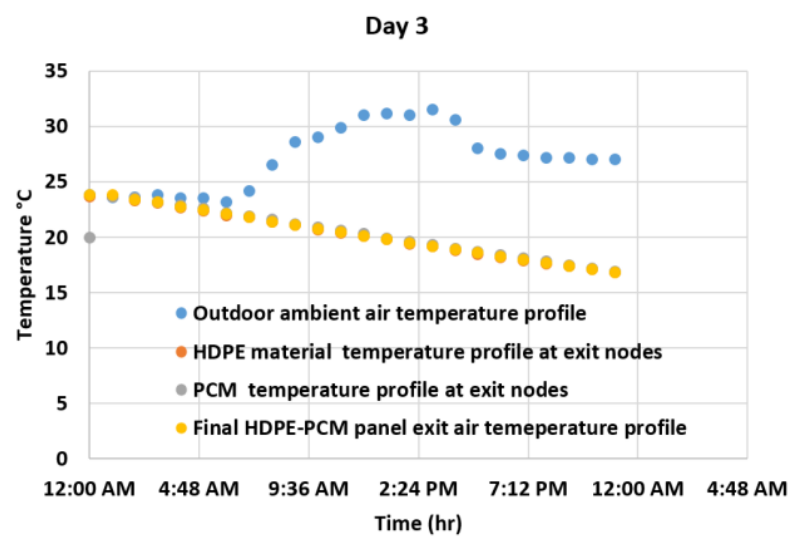

Figure 8: Graph of temperature against time for simulation day 3

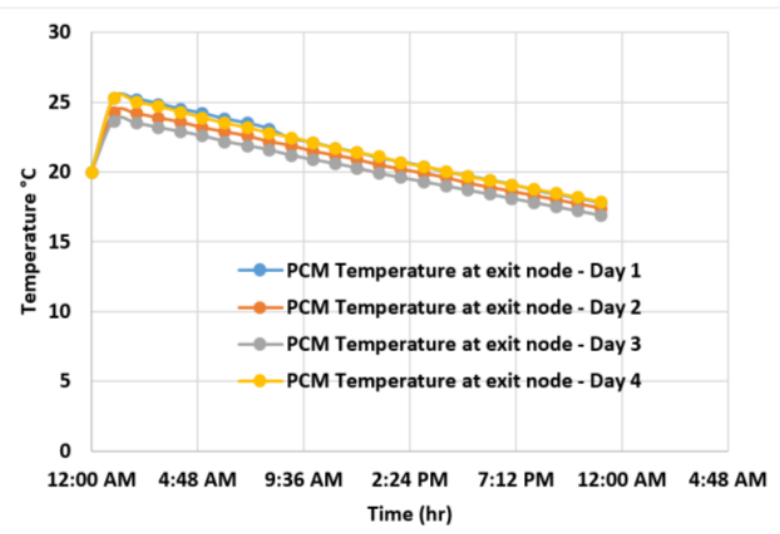

Figure 10: Graph of Temperature profiles of Paraffin wax at HDPE-PCM panel exit nodes

\section{CONCLUSION}

The author recommends that actual experiments and CFD analysis be conducted to validate the results obtained in this study. Furthermore, to ensure a completely green and passive cooling system, solar power may be used to power the axial flow fan(s) during the actual experiments. From the numerical

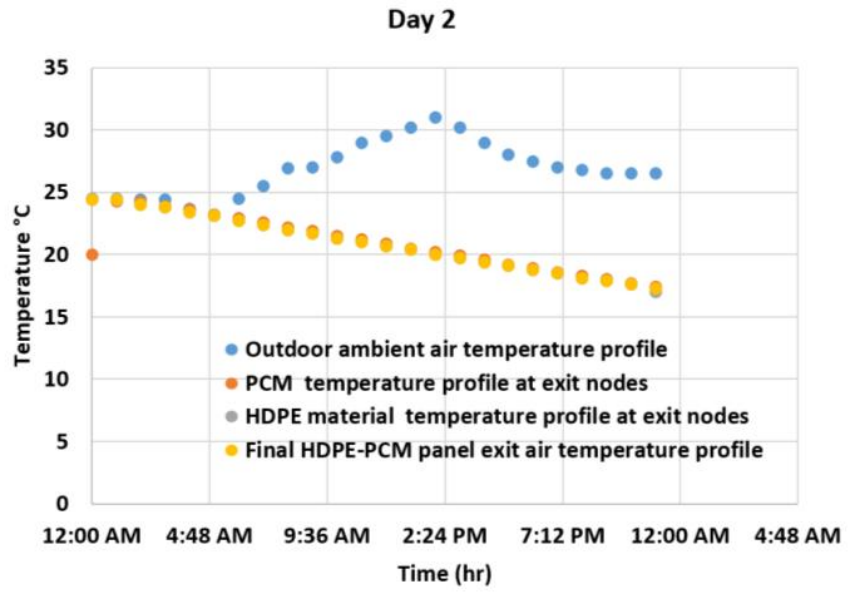

Figure 7: Graph of temperature against time for simulation day 2

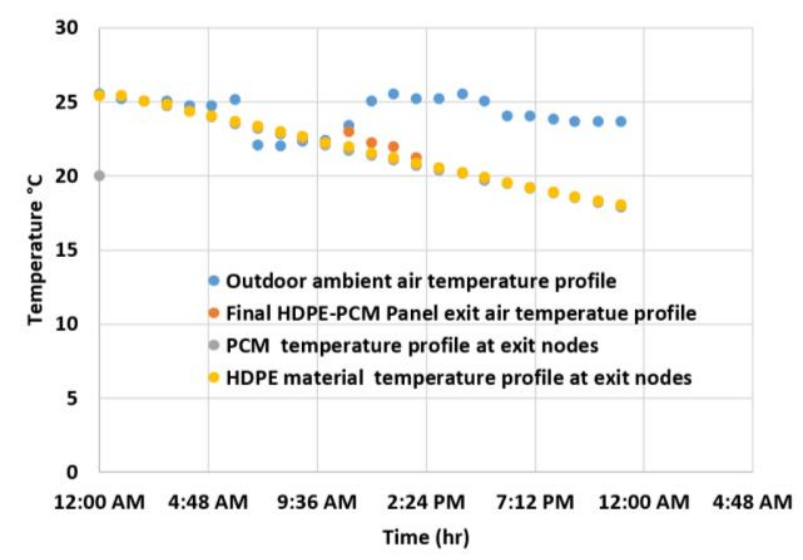

Figure 9: Graph of temperature against time for simulation day 4

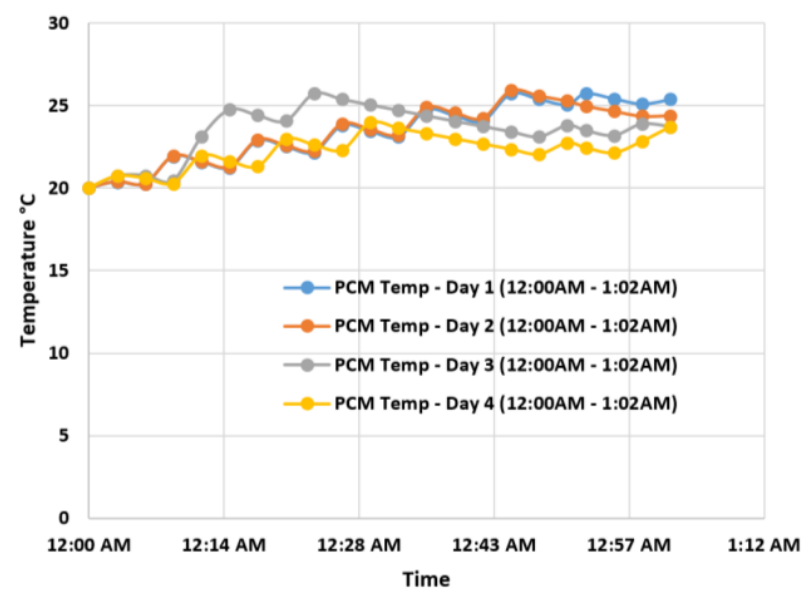

Figure 11: Graph of latent heat energy storage period of the PCM for simulation day 1-4

results obtained from the MATLAB programme software, it shows that exposing the HDPE-PCM panel system to high ambient temperature is capable of causing significant ambient temperature depressions of $7.1-10.2^{\circ} \mathrm{C}$ at the outlet duct of the HDPE-PCM panel system. Reverse suction DC fan(s) for indoor air quality recirculation and removal can be placed at Vol. 38, No. 2, April $2019 \quad 396$ 
strategic points on the steel walls, the HDPE-PCM panel medium can effectively cool the indoor space of the shipping container home.

\section{NOMENCLATURE}

$\mathrm{T}_{\mathrm{f}}$ - Temperature of air in HDPE-PCM panel medium, ${ }^{\circ} \mathrm{C}$

$\mathrm{T}_{\mathrm{w}}$ - Temperature of PCM(Paraffin wax), ${ }^{\circ} \mathrm{C}$

$\mathrm{T}_{\mathrm{p}}$ - Temperature of HDPE capsule material, ${ }^{\circ} \mathrm{C}$

$\mathrm{T}_{\mathrm{S}}$ - Surface node temperature, ${ }^{\circ} \mathrm{C}$

$\mathrm{T}_{\mathrm{r}}$ - Radiative temperature, ${ }^{\circ} \mathrm{C}$

$\mathrm{T}_{\mathrm{o}}$ - Estimated capsule outlet temperature, ${ }^{\circ} \mathrm{C}$

$\mathrm{T}_{\infty}$ - Hourly outdoor ambiemt air temperature , ${ }^{\circ} \mathrm{C}$

$\mathrm{T}_{\text {omid }}$ - Mid-day outdoor ambient air temperature, ${ }^{\circ} \mathrm{C}$

$\mathrm{T}_{\text {opeak }}$ - Peak daily ambient temperature, ${ }^{\circ} \mathrm{C}$

$\mathrm{T}_{\mathrm{lm}}$ - Log mean temperature, ${ }^{\circ} \mathrm{C}$

$\mathrm{k}_{\mathrm{p}}$-Thermal conductivity of HDPE panel material, $\mathrm{W} / \mathrm{mK}$

$\mathrm{k}_{\mathrm{f}}$ - Thermal conductivity of air, $\mathrm{W} / \mathrm{mK}$

$\mathrm{k}_{\mathrm{w}}-$ Thermal conductivity of paraffin wax, $\mathrm{W} / \mathrm{mK}$

$\emptyset$ - Heat generation, $\mathrm{W} / \mathrm{m}^{3}$

$\ell_{\mathrm{p}}$ - Density of HDPE panel material, $\mathrm{kg} / \mathrm{m}^{3}$

$\ell_{\mathrm{w}}-$ Density of PCM, $\mathrm{kg} / \mathrm{m}^{3}$

$\mathrm{C}_{\mathrm{pp}}$-Specific heat capacity of HDPE material, $\mathrm{J} / \mathrm{kg} \mathrm{K}$

$\mathrm{C}_{\mathrm{pf}}-$ Specific heat capacity of air, $\mathrm{J} / \mathrm{kg} \mathrm{K}$

$\mathrm{C}_{\mathrm{pw}}$-Specific heat capacity of PCM, $\mathrm{J} / \mathrm{kg} \mathrm{K}$

$A_{s}$ - External surface area of each capsule, $m^{2}$

$A_{p}$ - External surface area of HDPE-PCM panel, $m^{2}$

$A_{p t}-$ Area of HDPE-PCM panel with porosity, $\mathrm{m}^{2}$

$A_{D}-$ Axial fan duct area, $\mathrm{m}^{2}$

$\mathrm{h}_{\mathrm{w}}$ - Convective heat transfer coefficient of PCM in liquid phase, $\mathrm{W} / \mathrm{m}^{2} \mathrm{~K}$

$\mathrm{h}_{\mathrm{f}}-$ Convective heat transfer coefficient of air, $\mathrm{W} / \mathrm{m}^{2} \mathrm{~K}$

$\mathrm{h}_{\mathrm{r}}$ - Radiative heat transfer coefficient, $\mathrm{W} / \mathrm{m}^{2} \mathrm{~K}$

$r^{*}$ - Dimensionless distance from the centre of HDPE-PCM panel

$r_{h}$ - Diametral distance at end length of HDPE-PCM panel / panel outlet capsules, $\mathrm{m}$

$r$ - Diametral distance of HDPE-PCM capsule, $m$

$r_{0}$ - Diametral distance at start length of HDPE-PCM panel/panel inlet capsules, $\mathrm{m}$

$r_{1}$ - Diametral distance at end length HDPE-PCM first row capsules, $\mathrm{m}$

$\Delta r$ - Elemental diameter of HDPE-PCM capsule, $m$

i/2 - Node notation at mid-point of HDPE-PCM capsule

$\tau^{*}-$ Dimensionless time

$\theta-$ Dimensionless temperature
$\Delta t$ - Computational time interval

$\alpha_{\mathrm{p}}-$ Thermal diffusivity of HDPE-PCM, $\mathrm{m}^{2} / \mathrm{s}$

$\alpha_{\mathrm{w}}-$ Thermal diffusivity of PCM, $\mathrm{m}^{2} / \mathrm{s}$

$\mathrm{Nu}$ - Nusselt number

$\varepsilon-$ HDPE-PCM panel porosity

$\mathrm{Re}-$ Reynolds number

$\mathrm{P}_{\mathrm{r}}$ - Prandtl number

$\mathrm{F}_{\mathrm{o}}$ - Fourier number

$\mathrm{Q}_{\mathrm{v}}$-Volumetric mass flow rate of air, $\mathrm{m}^{3} / \mathrm{s}$

$\mathrm{h}$ - HDPE-PCM panel height/ length of the axial air flow region, $\mathrm{m}$

$V_{p}$ - Volume of paraffin wax storage in the HDPE capsules, $\mathrm{m}^{3}$

$\mathrm{V}_{\mathrm{o}}$ - Volume of the void fraction in the HDPE-PCM panel medium

$\mathrm{R}$-Radius of HDPE capsule, $\mathrm{m}$

$t_{p}$ - Thickness of the HDPE shell coating of capsules, $\mathrm{m}$

$\mathrm{m}_{\mathrm{s}}$ - Mass of a single capsule, $\mathrm{kg}$

$\mathrm{m}_{\mathrm{p}}$ - Mass of the HDPE-PCM panel medium, $\mathrm{kg}$

$\mathrm{N}_{\mathrm{c}}$ - Total number of HDPE capsules packed in the panel medium

$\mathrm{N}_{\mathrm{y}}$ - Number of HDPE capsules packed in the $\mathrm{y}$-axis

$\mathrm{N}_{\mathrm{x}}$ - Number of HDPE capsules packed in the $\mathrm{x}$-axis

$\mathrm{q}$ - Heat transfer rate, $\mathrm{W}$

$\epsilon-$ HDPE capsule material emissivity

б -Stefan boltzman constant, $\mathrm{W} / \mathrm{m}^{2} \mathrm{~K}^{4}$

$x$ - Space increment along HDPE-PCM panel height per element, $\mathrm{m}$

\section{Subscripts}

$\mathrm{p}$ - HDPE panel material

$\mathrm{f}-$ flowing air

$\mathrm{w}$ - Paraffin wax

$\mathrm{x}-\mathrm{x}$ axis

$y-y$ axis

avg - Average

0 - capsule node 0

1 - capsule node 1

2 - capsule node 2

3 - capsule node 3

cond - conduction

conv-convection

rad - radiation

\section{REFERENCES}

[1]. Hanan, M. T. Using passive cooling strategies to improve thermal performance and reduce energy consumption of residential buildings in U.A.E. 
buildings, Frontiers in Architectural Research 3(2), 154-165, 2014.

[2]. Inusa M. \& Alibaba, H.Z. Application of Passive Cooling Techniques in Residential Buildings; A Case Study of Northern Nigeria. International Journal of Engineering Research and Application 7(1), 22-30, 2017.

[3]. Dincer, I. \& Rosen, M. A. Thermal energy storage systems and applications. United Kingdom, John Wiley and Sons Ltd, 7-599, 2011.

[4]. Mohdlsa, M. H., Zhao, X. \& Yoshino, H. Preliminary study of passive cooling strategy using a combination of PCM and copper foam to increase thermal heat storage in building facade. Journal of Sustainability, 2, 2071-2381, 2010.

[5]. Arkar, C. \& Medved, S. Free cooling of a building using $\mathrm{PCM}$ heat storage integrated into the ventilation system, Solar Energy 81, 10781087,2007.

[6]. Zhang, Y., Zhou, G., Lin, K., Zhang, Q. \& Di, D. Application of latent heat thermal energy storage in buildings; state of the art and outlook, Building and Environment 42, 2197-2209, 2007.

[7]. Stritith, U. \& Butala, V. Energy saving in building with PCM cold storage, International Journal of Energy Research 31, 1532-1544, 2007.

[8]. Medina, M. A., King, J. B. \& Zhang, M. On the heat transfer rate reduction of structural insulated panels (SIPs) out-filled with phase change materials (PCMs), Energy 33, 667-678, 2008.

[9]. Medved, S. \& Arkar, C. Correlation between the local climate and the free-cooling potential of latent heat storage, Energy and Buildings 40, 429-437, 2008.
[10]. Lamberg, P., Lehtiniemi, R. \& Henell, A. Numerical and experimental investigation of melting and freezing processes in phase change material storage. International Journal of Thermal Science, 43, 277-287, 2004.

[11]. Udosen, A. N,. Transient numerical models for predicting the performance of encapsulated PCM under varying ambient temperatures for cooling application. International Journal of Scientific \& Engineering Research, 9(3), 253-260, 2018.

[12]. Enibe, S. O. Thermal analysis of a natural circulation solar air heater with phase change material energy storage. Renewable Energy, 28(14), 2269-2299, 2003.

[13]. Johannes, K., Borderon, J., Virgone, J., Cantin, R., \& Kuznik, F.. Numerical analysis of the thermal comfort in a retrofitted family house using a PCM/Air Heat Exchanger-System. 12th Conference of International Building Performance Simulation Association, Sydney, 720-726, 2011.

[14]. Singh, R., Saini, R., \& Saini, J. Simulated performance of packed bed solar energy storage system having storage material elements of large size (Part I). The Open Fuels and Energy Science Journal, I, 91-96, 2008.

[15]. Incropera, De Witt, Bergman, T. \& Lavine, A.. Fundamentals of heat and mass transfer. Sixth Edition. Wiley Companies, 2011.

[16]. Udosen, A. N, Modeling of the performance of Micro-Encapsulated Phase Change Material for Maintenance of Comfortable Space Temperature. An M. Eng Thesis submitted to Federal University of Technology, Owerri, 2015. 